\title{
Restructuring of genomic provinces of surface ocean plankton under climate change
}

Paul Frémont ${ }^{1,2^{*}}$, Marion Gehlen ${ }^{3 *}$, Mathieu Vrac ${ }^{3}$, Jade Leconte ${ }^{1,2}$, Patrick Wincker ${ }^{1,2}$, Daniele Iudicone ${ }^{4}$, Olivier Jaillon ${ }^{1,2^{*}}$

${ }^{1}$ Génomique Métabolique, Genoscope, Institut François Jacob, CEA, CNRS, Université d'Evry, Université ParisSaclay, 91057 Evry, France. ${ }^{2}$ Research Federation for the study of Global Ocean Systems Ecology and Evolution, FR2022/Tara Oceans, Paris, France. ${ }^{3}$ LSCE-IPSL, CEA/CNRS/Université Paris-Saclay, Gif-surYvette, France. ${ }^{4}$ Stazione Zoologica Anton Dhorn. Villa Comunale, 80121, Naples, Italy.

*Corresponding authors: pfremont@genoscope.cns.fr; marion.gehlen@lsce.ipsl.fr; ojaillon@genoscope.cns.fr

Abstract

The impact of climate change on diversity, functioning and biogeography of marine plankton is a major unresolved scientific issue. Here, niche theory is applied on plankton metagenomes sampled during the Tara Oceans expedition to derive panocean geographical structuring in climato-genomic provinces characterized by signature genomes for 6 size fractions, from viruses to meso-zooplankton. Assuming a high warming scenario (RCP8.5), the identified tropical provinces would expand and temperate provinces would shrink. Poleward shifts are projected for $96 \%$ of provinces in five major basins leading to their reorganization over $\sim 50 \%$ of the surface ocean south of $60^{\circ} \mathrm{N}$, of which $3 \%$ correspond to novel assemblages of provinces. Sea surface temperature is identified as the main driver and accounts only for $\sim 51 \%$ of the changes followed by phosphate (11\%) and salinity $(10.3 \%)$. These results demonstrate the potential of integration of genomics with physico-chemical data for higher scale modeling and understanding of ocean ecosystems.

Planktonic communities are composed of complex and heterogeneous assemblages of small animals, small single-celled eukaryotes (protists), prokaryotes and viruses - that drift with currents. They contribute to the regulation of the Earth system notably through primary production via photosynthesis ${ }^{1}$, carbon export to the deep oceans ${ }^{2,3}$ and form the base of the food webs that sustain the whole trophic chain in the oceans and beyond 4 .

The composition of communities is known to vary over time at a given site with daily 5 to seasonal fluctuations $^{6}$ following environmental variability ${ }^{7,8}$. Overlying these relatively 
short scale spatio-temporal variations, a more macroscale partitioning of the ocean was evidenced by different combinations of biological and physico-chemical data9-11, and recently at the resolution of community genomics ${ }^{12}$. The basin scale biogeographical structure was proposed to result from a combination of multiple bio-physico-chemical processes named the seascape ${ }^{7,8}$, including both abiotic and biotic interactions ${ }^{13}$, neutral genetic drift ${ }^{14}$, natural selection ${ }^{15-17}$, temperature variations, nutrient supply but also advection and mixing along currents ${ }^{12,14}$. Today, knowledge of global scale plankton biogeography at the DNA level is in its infancy. We lack understanding and theoretical explanations for the emergence and maintenance of biogeographical patterns at genomic resolution. Omics data (i.e. the DNA/RNA sequences representative of the variety of coding and non-coding sequences of organisms) provide the appropriate resolution to track and record global biogeographical features ${ }^{12}$, modulation of the repertoire of expressed genes in a community in response to environmental conditions $s^{2,18,19}$ as well as eco-evolutionary processes ${ }^{14,16,17}$. Importantly, metagenomic sequencing can be consistently analyzed across plankton organisms as recently demonstrated by global expeditions ${ }^{20-23}$. Furthermore, the strong links between plankton and environmental conditions suggest potentially major consequences of climate change on community composition and biogeography ${ }^{24,25}$. Time series observations have highlighted recent changes in the planktonic ecosystem attributed to this anthropogenic pressure, such as changes in community composition ${ }^{26-28}$ or poleward shifts of some species $^{29,30}$. These changes are expected to intensify with ongoing climate warming and could lead to major reorganizations in plankton community composition 24,25 , with a potential decline in diversity ${ }^{31-33}$. Another major consequence of a global reorganization of the seascape on biological systems (e.g. growth, grazing) would be a decrease of primary production at mid-latitudes and an increase at higher latitudes ${ }^{34}$. Here we report a global structure of plankton biogeography based on metagenomic data using niche models and its putative modifications under climate change. First, we show that environmental niches ${ }^{35}$, i.e. the envelope of environmental parameters suitable for an organism or a population, can be defined at the scale of genomic provinces across 6 organism size fractions representing major plankton groups from nano- (viruses) to mesozooplankton (small metazoans). Then, we spatially extrapolate their niches into climato- 
genomic provinces to depict the structure of plankton biogeography of all but arctic regions

for each size fraction and for all combined. Then, considering the same niches, we assess putative spatial reorganization of the same provinces and their associated environmental drivers under climate change at the end of the century. Niche models and signature genomes from genomic provinces

We use 38 previously defined genomic provinces ${ }^{12}$ containing at least 4 sampling sites; they correspond to 595 metagenomes for 6 size fractions (ranging from 0 to $2000 \mu \mathrm{m}$ ) and sampled in 95 sites from all oceans except the Arctic (Supplementary Figs. 1-2).

To compute and test the validity of realized environmental niches, we train four machine learning techniques to probabilistically associate genomic provinces with environmental data: sea surface temperature, salinity, three macronutrients (dissolved silica, nitrate and phosphate), one micronutrient (dissolved iron) plus a seasonality index of nitrate. A valid environmental niche is obtained for 27 out of 38 initial provinces (71\%) comforting their definition and covering 529 samples out of 595 (89\%, Supplementary Fig. 2). Rejected provinces contain relatively few stations (mean of $6 \pm 2.6$ versus $19 \pm 15.3$ for valid provinces, p-value $<10^{-3}$ Wilcoxon test). For spatial and temporal extrapolations of the provinces presented below, we use the ensemble model approach ${ }^{36}$ that considers mean predictions of machine learning techniques.

The signal of ocean partitioning is likely due to abundant and compact genomes whose geographical distributions closely match provinces. Within a collection of 523 prokaryotic and 713 eukaryotic genomes 37,38 from Tara Oceans samples, we find signature genomes for all but 4 provinces. In total, they correspond to respectively 96 and 52 of the genomes and their taxonomies are coherent with the size fractions (Fig. 1 for eukaryotes and Supplementary Fig. 3 for prokaryotes). Some of them correspond to unexplored lineages highlighting the gap of knowledge for organisms that structure plankton biogeography and the strength of a rationale devoid of any a priori on reference genomes or species.

\section{Structure of present day biogeography of plankton}

91 probable provinces, named hereafter as dominant and assigned to a climatic annotation

92 (Supplementary Table 1), on each $1^{\circ} \times 1^{\circ}$ resolution grid point using 2006-13 W0A13 climatology ${ }^{39}$ (Supplementary Fig. 4 and Fig. 3). 
Overall, in agreement with previous observations ${ }^{12}$, provinces of large size fractions $(>20$ $\mu \mathrm{m}$ ) are wider and partially decoupled from those of smaller size fractions, probably due to differential responses to oceanic circulation and environmental variations, different life cycle constraints, lifestyles $7,8,12$ and trophic networks positions ${ }^{40}$. Biogeographies of small metazoans that enrich the largest size fractions (180-2000 $\mu \mathrm{m}$ and 20-180 $\mu \mathrm{m}$ ) are broadly aligned with latitudinal bands (tropico-equatorial, temperate and (sub)-polar) dominated by a single province (Fig. 2a,b). A more complex oceanic structuring emerges for the smaller size fractions $(<20 \mu \mathrm{m})$ (Fig. 2c-f) with several provinces per large geographical region. Taking size fraction 0.8-5 $\mu \mathrm{m}$ enriched in small protists (Fig. 2d) as an example, distinct provinces are identified for oligotrophic gyres in the Atlantic and Pacific Oceans, and one for the nutrient-rich equatorial upwelling region. A complex pattern of provinces, mostly latitudinal, is also found for the bacteria enriched size class (Fig. 2e, 0.22-3 $\mu \mathrm{m}$ ) and the virus enriched size class (Fig. 2f, 0-0.2 $\mu \mathrm{m}$ ) though less clearly linked to large-scale oceanographic regions. A single province extending from temperate to polar regions emerges from the size fraction 5-20 $\mu$ m enriched in protists (Fig. 2c), for which a smaller number of samples is available (Supplementary Fig. 2b-c), which probably biases this result. Finally, we use PHATE ${ }^{41}$ dimension reduction algorithm to combine all provinces for all size classes into a single consensus biogeography revealing 4 or 7 robust clusters (Fig.

112 2g,h). The 4 cluster consensus biogeography is mainly latitudinally organized distinguishing polar, subpolar, temperate and tropico-equatorial regions. The 7 cluster consensus biogeography distinguishes the equatorial pacific upwelling biome and three subpolar biomes that most likely reflect the chemico-physical structuring of the Southern Ocean and known polar fronts (red lines Fig. 2h). However, learning data are scarcer south of $60^{\circ} \mathrm{S}$ so these extrapolations need to be taken with caution.

118 Previous ocean partitioning either in biomes ${ }^{9-11}$ or biogeochemical provinces (BGCPs) ${ }^{9,11}$ are based on physico-biogeochemical characteristics including SST ${ }^{9-11}$, chlorophyll $a^{9-11}$, 120 salinity ${ }^{9-11}$, bathymetry9,11, mixed layer depth ${ }^{10}$ or ice fraction ${ }^{10}$. Considering three of these 121 partitions as examples we notice differences with our partitions (Supplementary Fig. 7-8) 122 for example in terms of number of regions in the considered oceans (56 for 2013 123 Reygondeau et al. BGCPs ${ }^{11}, 17$ for Fay and McKingley ${ }^{10}$ ) and structure (the coastal biome for 2013 Reygondeau et al. biomes ${ }^{11}$ ). Numerical comparison of our partitions with others 
(Methods), reveals low similarity between them, the highest being with Reygondeau biomes (Supplementary Figs. 7-9). However, biomes and BGCP frontiers closely match our province frontiers in many cases. Near the frontiers, dominant provinces have smaller probabilities in agreement with smooth transitions instead of sharp boundaries as already proposed $^{9}$ and with a seasonal variability of the frontiers ${ }^{11}$ (Supplementary Fig 7). Some of these transitions are very large and match entire BGCPs, for example in subtropical North Atlantic and subpolar areas where high annual variations are well known ${ }^{11}$.

\section{Future changes in plankton biogeography structure}

We assess the impacts of climate change on plankton biogeography at the end of the $21^{\text {st }}$ century following the Representative Concentration Pathway 8.5 (RCP8.5) ${ }^{42}$ greenhouse gas emission scenario. To consistently compare projections of present and future biogeographies with coherent spatial structures, we use a bias-adjusted mean of 6 Earth System Model (ESM) climatologies (Supplementary Table 2, Supplementary Fig. 10, Materials and Methods). The highest warming $\left(7.2^{\circ} \mathrm{C}\right)$ is located off the east coast of Canada in the North Atlantic while complex patterns of salinity and nutrient variations are projected in all oceans (Supplementary Figure 11). According to this scenario, future temperature at most sampling sites will be higher than the mean and maximum contemporary temperature within their current province (Supplementary Fig. 12).

Our projections indicate multiple large-scale changes in biogeographical structure including plankton organism size-dependent province expansions or shrinkages and shifts (Supplementary Fig. 13-15). A change in the dominant province in at least one size fraction would occur over $60.1 \%$ of the ocean surface, ranging from $12 \%(20-180 \mu \mathrm{m})$ to $31 \%$ (0.8-5 $\mu \mathrm{m})$ (Table 1).

Centroids of provinces with dominance areas larger than $10^{6} \mathrm{~km}^{2}$ within a basin would be moved at least $200 \mathrm{~km}$ away for $77 \%$ of them, $96 \%$ of which move poleward (Supplementary Figs. 14 and 14). Most longitudinal shift distances are smaller (50\% $<190$ $\mathrm{km}$ ) but a few are larger than $1000 \mathrm{~km}$ while the distribution of latitudinal shifts is more concentrated around the mean $(290 \mathrm{~km})$ with no shifts superior to $1000 \mathrm{~km}$ (Supplementary Fig. 15b). These important longitudinal shifts corroborate existing projections $24,43,44$ and differ from trivial poleward shifts due to temperature increase, reflecting more complex spatial rearrangements of the other environmental drivers 
156 (Supplementary Fig. 11). We find an average displacement speed of the provinces' 157 centroids of $76 \pm 79 \mathrm{~km} \cdot \mathrm{dec}^{-1}$ (latitudinally mean of $34 \pm 82 \mathrm{~km} \cdot \mathrm{dec}^{-1}$ and $59 \pm 82 \mathrm{~km} \cdot \mathrm{dec}^{-1}$ 158 longitudinally; median of $47 \mathrm{~km} \cdot \mathrm{dec}^{-1}, 23 \mathrm{~km} \cdot \mathrm{dec}^{-1}$ latitudinally and $27 \mathrm{~km} \cdot \mathrm{dec}^{-1}$ 159 longitudinally). We project phytoplankton provinces displacements similar to previously

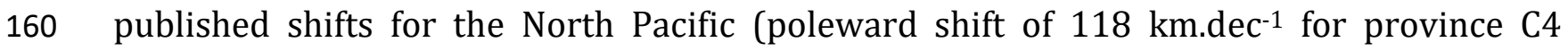
161 versus $100 \mathrm{~km} \cdot \mathrm{dec}^{-1}$ for the subtropical biome of Polovina et al. ${ }^{44}$ and eastward shift of 195 $162 \mathrm{~km} \mathrm{dec}^{-1}$ for province C9 versus $200 \mathrm{~km} \mathrm{dec}^{-1}$ for the equatorial biome of Polovina et al. ${ }^{44}$ ). 163 For all size fractions, climate change would lead to a poleward expansion of tropical and 164 equatorial provinces at the expense of temperate provinces (Table 1 and Supplementary 165 Fig. 13). This is illustrated for the size fraction 180-2000 by the example of the temperate province F5 (Supplementary Fig. 16) for which significant shrinkage is projected in the five major ocean basins. In the North Atlantic, its centroid would move approximately $800 \mathrm{~km}$ to the northeast (Supplementary Fig. 16c).

To simplify comparisons between future and present biogeographies, we combine all projections into two comparable consensus maps (Fig. 2e,f). Some particularly visible patterns of geographical reorganization are common to several or even all size fractions and visible on the consensus maps (Fig. 2e,f compared to Fig. 2a-d and Supplementary Fig. 13). For example, the tropico-equatorial and tropical provinces expand in all size fractions and the provinces including the pacific equatorial upwelling shrink for size fractions 175 smaller than $20 \mu \mathrm{m}$.

176 To further quantify patterns of expansion or shrinkage, we calculate the surface covered by 177 the dominant provinces weighted by probabilities of presence (Supplementary Fig. 17, 178 Supplementary Table 1). In this way, dominant provinces are defined on 100\% of the 179 surface ocean (327 millions of $\mathrm{km}^{2}$ ) but their presence probabilities correspond to the 180 equivalent of 45 to $74 \%$ (due to sampling variability and niche overlaps) of the surface ocean depending on plankton size fraction (Table 1). Overall, our results indicate 182 expansions of the surface of tropical and tropico-equatorial provinces but in very different ways depending on the size fractions of organisms. The surface area of temperate provinces is $\sim 22$ million $\mathrm{km}^{2}$ on average (from $10 \mathrm{Mkm}^{2}$ for $0-0.2 \mu \mathrm{m}$ to $49 \mathrm{Mkm}^{2}$ for 20$180 \mu \mathrm{m}$ ) and should decrease by $36 \%$ on average (from $-20 \%$ for $5-20 \mu \mathrm{m}$ up to $-54 \%$ for 
million $\mathrm{km}^{2}$ on average (from $86 \mathrm{Mkm}^{2}$ for $0.8-5 \mu \mathrm{m}$ up to $169 \mathrm{Mkm}^{2}$ for $180-2000 \mu \mathrm{m}$ ) and their coverage should increase by $32 \%$ on average (from $+13 \%$ for $0-0.2 \mu \mathrm{m}$ up to $+75 \%$ for $0.8-5 \mu \mathrm{m},+25$ million $\mathrm{km}^{2}$ on average) (Supplementary Fig. 17 and Supplementary Table 1).

We calculate at each grid point a single dissimilarity index (Materials and Methods) between probabilities of future and present dominant provinces for all size fractions combined (Fig. 4a). Areas located between future and present borders of expanding and shrinking provinces would be the most subject to replacements by other contemporary provinces, as exemplified by the poleward retraction of the southern/northern edges of the temperate provinces (red arrows on Fig. 4a, Table 1). High dissimilarities are obtained over northern $\left(25^{\circ}\right.$ to $\left.60^{\circ}\right)$ and symmetrically southern (-25 to $\left.-60^{\circ}\right)$ temperate regions (mean of 0.29 and 0.24 respectively). Despite important environmental changes in austral and equatorial regions (Supplementary Fig. 11) and projected change in diversity ${ }^{31-33}$ and biomass ${ }^{45}$, the contemporary provinces remain the most probable at the end of the century using our statistical models (mean dissimilarities of 0.18 and 0.02 respectively) as no known contemporary provinces could replace them.

To further study the decoupling between provinces of different size fractions in the future we considered the assemblages of dominant provinces of each size fraction. By using two differently stringent criteria, from 45.3 to $57.1 \%$ of ocean surface, mainly located in temperate regions, would be inhabited in 2090-99 by assemblages that exist elsewhere in 2006-15 (Fig. 4b versus Fig. 4c). Contemporary assemblages would disappear on 3.5 to $3.8 \%$ of the surface, and, conversely, novel assemblages, not encountered today, would cover 2.9 to $3.0 \%$ of the surface. These areas appear relatively small but they include some important economic zones (Fig 4b, Supplementary Fig. 18). On $41.8 \%$ to $51.8 \%$ of the surface of the main fisheries and $41.2 \%$ to $54.2 \%$ of Exclusive Economic Zones (Materials and Methods), future assemblages would differ from those present today (Supplementary Fig. 18).

\section{Drivers of plankton biogeography reorganization}

We quantify the relative importance of considered environmental parameters (temperature, salinity, dissolved silica, macronutrients and seasonality of nitrate) into niche definition and in driving future changes of the structure of plankton biogeography. 
Among environmental properties that define the niches, temperature is the first influential parameter (for 19 niches out of 27) but only at $22.6 \%$ on average. Particularly, the distribution of relative influences of temperature is spread over a much wider range than that of other parameters (Supplementary Fig. 18a).

The relative impact of each environmental parameter is calculated ${ }^{24}$ for each site presenting a significant dissimilarity between 2006-15 and 2090-99 (Fig 5a). Overall, SST would be responsible for reorganization of half of the provinces followed by Phosphate (11 \%) and Salinity (10.3\%) (Supplementary Fig. 20). SST is the primary driver over the majority of the ocean (Fig. 5a). In some regions, salinity (e.g. eastern North Atlantic) and Phosphate (e.g. equatorial region) dominate (Fig. 5a) and excluding the effect of SST, they are the primary drivers of global reorganization of the provinces (Fig. 5 b). The impact of SST varies across size classes with a significantly higher contribution in large size classes $(>20 \mu \mathrm{m})$ compared to the small ones (mean of $\sim 73 \%$ versus $\sim 49 \%$; Fig. $5 \mathrm{c}$ ). Even though the contribution of combined nutrients to niche definition is similar for small and large size classes under present day conditions (mean of $\sim 56 \%$ versus $\sim 61 \%$, Supplementary Fig. 19, Supplementary Table 3), their future projected variations have a higher relative impact on the reorganization of small organisms' biogeographies (mean of $\sim 39 \%$ versus $\sim 20 \%$, t-test p-value < 0.05, Supplementary Fig. 19, Supplementary Table 3). For instance, in the tropical zone, the shrinkage of the equatorial province (province C9, size fraction $0.8-5 \mu \mathrm{m}$, Fig. 2b,d, Supplementary Fig. 16e) is driven at $24 \%$ by reduction of dissolved phosphate concentrations and at $25 \%$ by SST increase. In contrast, SST and Salinity would drive respectively at $56 \%$ and $16 \%$ the shrinkage of the temperate province F5 of size fraction 180-2000 $\mu \mathrm{m}$ (Supplementary Fig. 16d versus e). Non-poleward shifts are found only within small size fractions $(<20 \mu \mathrm{m})$ (Supplementary Fig. 14, 15) highlighting differential responses to nutrients and SST changes between large and small size classes, the latter being enriched in phytoplankton that directly rely on nutrient supplies.

\section{Discussion}

We propose a novel partitioning of the ocean in plankton size dependent climato-genomic provinces, complementing pioneer and recent efforts based on other bio-physico-chemical data ${ }^{9-11}$. Though they are initially built at genomic scale, our biogeographies paradoxically reveal basin scale provinces that are larger than BGCPs ${ }^{11}$ and biomes ${ }^{10}$, and probably 
relatively stable across seasons evoking limited effects of seasonality on frontiers positions of BGCPs provinces ${ }^{11}$. We propose that this apparent paradox emerges from the combination of the scale, nature and resolution of sampling. First, two proximal samples from the Tara Oceans expedition are separated by $\sim 300 \mathrm{~km}$ on average sampled over three years; this relatively large spatio-temporal scale overlies shorter scale compositional variations previously observed ${ }^{5,6}$. Second, our estimates of plankton community dissimilarities are highly resolutive; they are computed at genomic scale with billions of small DNA fragments ${ }^{12,20}$ thus smoothing the more discrete species level signal. Together, from these combinations of processes and patterns occurring at multiple scales emerge basin scale provinces associated with coherent environmental niches and signature genomes.

These climato-genomic provinces are structured in broad latitudinal bands with smaller organisms $(<20 \mu \mathrm{m})$ displaying more complex patterns and partially decoupled from larger organisms. This decoupling is the result of distinct statistical links between provinces based on organism size fractions and environmental parameters and could reflect their respective trophic modes ${ }^{40}$.

Complex changes of the parameters defining the niches are projected under climate change leading to size-dependent modifications of biogeographical patterns, as for example smaller organisms being more sensitive to nutrient changes. Assuming the maintenance of environmental characteristics that define the climato-genomic provinces, climate change is projected to restructure them over approximately $50 \%$ of surface oceans south of $60^{\circ} \mathrm{N}$ by the end of the century (Fig. 4). The largest reorganization is detected in subtropical and temperate regions in agreement with other studies ${ }^{32,44}$ and is accompanied by appearance and disappearance of size-fractionated provinces' assemblages. For tropico-equatorial and austral regions, out of contemporary range and novel environmental conditions are projected. While some studies extrapolate important diversity and biomass changes in these zones ${ }^{31-33,45}$, here we project shifts of their boundaries and maintain their climatic label. However, the present approach does not account for putative changes in community composition nor the emergence of novel niches over these regions for which novel environmental selection pressure is expected. 
279 Overall, our projections for the end of the century do not take into account possible future 280 changes of major bio-physico-chemical factors such as dynamics of community mixing, 281 trophic interactions through transport 46 , the potential dynamics of the genomes $14,16,17$

282 (adaptation or acclimation) and biomass variations ${ }^{45}$. New sampling in current and future 283 expeditions ${ }^{47}$, as well as ongoing technological improvements in bio-physico-chemical 284 characterization of seawater samples ${ }^{38,47,48}$ will soon refine functional ${ }^{18,49}$, environmental 285 (micronutrients ${ }^{50}$ ) and phylogenetic ${ }^{16,17}$ characterization of plankton ecosystems for various biological entities (genotypes, species or communities) and spatio-temporal 287 scales ${ }^{47}$. Ultimately, crossing this varied information will allow a better understanding of the conditions of emergence of ecological niches in the seascape and their response to a changing ocean.

\section{References}

291 1. Field, C. B., Behrenfeld, M. J., Randerson, J. T. \& Falkowski, P. Primary production of the biosphere: Integrating terrestrial and oceanic components. Science (80-. ). (1998). doi:10.1126/science.281.5374.237

2942 Guidi, L. et al. Plankton networks driving carbon export in the oligotrophic ocean. Nature (2016). doi:10.1038/nature16942

296 3. Henson, S. A., Sanders, R. \& Madsen, E. Global patterns in efficiency of particulate organic carbon export and transfer to the deep ocean. Global Biogeochem. Cycles (2012). doi:10.1029/2011GB004099

4. Azam, F. et al. The Ecological Role of Water-Column Microbes in the Sea. Mar. Ecol. Prog. Ser.

301 5. Saab, M. A. abi. Day-to-day variation in phytoplankton assemblages during spring blooming 302 in a fixed station along the Lebanese coastline. J. Plankton Res. (1992). doi:10.1093/plankt/14.8.1099

6. Djurhuus, A. et al. Environmental DNA reveals seasonal shifts and potential interactions in a marine community. Nat. Commun. (2020). doi:10.1038/s41467-019-14105-1

7. Kavanaugh, M. T. et al. Seascapes as a new vernacular for pelagic ocean monitoring,

308 8. Steele, J. H. The ocean 'landscape'. Landsc. Ecol. (1989). doi:10.1007/BF00131537

309 9. Longhurst, A. R. Ecological Geography of the Sea. Ecological Geography of the Sea (2007). doi:10.1016/B978-0-12-455521-1.X5000-1 
10. Fay, A. R. \& McKinley, G. A. Global open-ocean biomes: Mean and temporal variability. Earth Syst. Sci. Data (2014). doi:10.5194/essd-6-273-2014

11. Reygondeau, G. et al. Dynamic biogeochemical provinces in the global ocean. Global Biogeochem. Cycles (2013). doi:10.1002/gbc.20089

12. Richter, D. J. et al. Genomic evidence for global ocean plankton biogeography shaped by large-scale current systems. bioRxiv 867739 (2019). doi:10.1101/867739

13. Dutkiewicz, S. et al. Dimensions of marine phytoplankton diversity. Biogeosciences (2020). doi:10.5194/bg-17-609-2020

14. Hellweger, F. L., Van Sebille, E. \& Fredrick, N. D. Biogeographic patterns in ocean microbes emerge in a neutral agent-based model. Science (80-. ). (2014). doi:10.1126/science.1254421

15. Sauterey, B., Ward, B., Rault, J., Bowler, C. \& Claessen, D. The Implications of Eco-Evolutionary

16. Laso-Jadart, R. et al. Investigating population-scale allelic differential expression in wild populations of Oithona similis (Cyclopoida, Claus, 1866). Ecol. Evol. (2020). doi:10.1002/ece3.6588

17. Delmont, T. O. et al. Single-amino acid variants reveal evolutionary processes that shape the biogeography of a global SAR11 subclade. Elife (2019). doi:10.7554/eLife.46497

18. Carradec, Q. et al. A global ocean atlas of eukaryotic genes. Nat. Commun. (2018). doi:10.1038/s41467-017-02342-1

19. Salazar, G. et al. Gene Expression Changes and Community Turnover Differentially Shape the Global Ocean Metatranscriptome. Cell (2019). doi:10.1016/j.cell.2019.10.014

20. Alberti, A. et al. Viral to metazoan marine plankton nucleotide sequences from the Tara Oceans expedition. Sci. Data (2017). doi:10.1038/sdata.2017.93

21. Pesant, S. et al. Open science resources for the discovery and analysis of Tara Oceans data. Sci. Data (2015). doi:10.1038/sdata.2015.23

22. Karsenti, E. et al. A holistic approach to marine Eco-systems biology. PLoS Biol. (2011). doi:10.1371/journal.pbio.1001177

23. Duarte, C. M. Seafaring in the 21st century: The Malaspina 2010 circumnavigation expedition. Limnology and Oceanography Bulletin (2015). doi:10.1002/lob.10008

24. Barton, A. D., Irwin, A. J., Finkel, Z. V. \& Stock, C. A. Anthropogenic climate change drives shift and shuffle in North Atlantic phytoplankton communities. Proc. Natl. Acad. Sci. (2016). doi:10.1073/pnas.1519080113 
25. Benedetti, F., Guilhaumon, F., Adloff, F. \& Ayata, S. D. Investigating uncertainties in zooplankton composition shifts under climate change scenarios in the Mediterranean Sea. Ecography (Cop.). (2018). doi:10.1111/ecog.02434

26. Beaugrand, G. et al. Prediction of unprecedented biological shifts in the global ocean. Nature Climate Change (2019). doi:10.1038/s41558-019-0420-1

27. McMahon, K. W., McCarthy, M. D., Sherwood, O. A., Larsen, T. \& Guilderson, T. P. Millennialscale plankton regime shifts in the subtropical North Pacific Ocean. Science (80-. ). (2015). doi:10.1126/science.aaa9942

28. Rivero-Calle, S., Gnanadesikan, A., Del Castillo, C. E., Balch, W. M. \& Guikema, S. D. Multidecadal increase in North Atlantic coccolithophores and the potential role of rising CO2. Science (80-. ). (2015). doi:10.1126/science.aaa8026

29. Beaugrand, G. Decadal changes in climate and ecosystems in the North Atlantic Ocean and adjacent seas. Deep. Res. Part II Top. Stud. Oceanogr. (2009). doi:10.1016/j.dsr2.2008.12.022

30. Pinsky, M. L., Worm, B., Fogarty, M. J., Sarmiento, J. L. \& Levin, S. A. Marine taxa track local climate velocities. Science (80-. ). (2013). doi:10.1126/science.1239352

31. Thomas, M. K., Kremer, C. T., Klausmeier, C. A. \& Litchman, E. A global pattern of thermal adaptation in marine phytoplankton. Science (80-. ). (2012). doi:10.1126/science.1224836

32. Busseni, G. et al. Large scale patterns of marine diatom richness: Drivers and trends in a changing ocean. Glob. Ecol. Biogeogr. (2020). doi:10.1111/geb.13161

33. Ibarbalz, F. M. et al. Global Trends in Marine Plankton Diversity across Kingdoms of Life. Cell (2019). doi:10.1016/j.cell.2019.10.008

34. Bopp, L. et al. Multiple stressors of ocean ecosystems in the 21st century: Projections with CMIP5 models. Biogeosciences (2013). doi:10.5194/bg-10-6225-2013

35. Hutchinson, G. E. Concludig remarks. Cold Spring Harb. Symp. Quant. Biol. (1957).

36. Jones, M. C. \& Cheung, W. W. L. Multi-model ensemble projections of climate change effects on global marine biodiversity. ICES J. Mar. Sci. (2015). doi:10.1093/icesjms/fsu172

37. Delmont, T. O. et al. Nitrogen-fixing populations of Planctomycetes and Proteobacteria are abundant in surface ocean metagenomes. Nat. Microbiol. (2018). doi:10.1038/s41564-0180176-9

38. Delmont, T. O. et al. Functional repertoire convergence of distantly related eukaryotic plankton lineages revealed by genome-resolved metagenomics. bioRxiv 2020.10.15.341214 (2020). doi:10.1101/2020.10.15.341214

39. Boyer, T. P. et al. WORLD OCEAN DATABASE 2013, NOAA Atlas NESDIS 72. Sydney Levitus, 
40. Sunagawa, S. et al. Tara Oceans: towards global ocean ecosystems biology. Nature Reviews Microbiology (2020). doi:10.1038/s41579-020-0364-5

41. Moon, K. R. et al. Visualizing structure and transitions in high-dimensional biological data. Nat. Biotechnol. (2019). doi:10.1038/s41587-019-0336-3

42. van Vuuren, D. P. et al. The representative concentration pathways: An overview. Clim. Change (2011). doi:10.1007/s10584-011-0148-z

43. Marinov, I. et al. North-South asymmetry in the modeled phytoplankton community response to climate change over the 21st century. Global Biogeochem. Cycles (2013). doi:10.1002/2013GB004599

44. Polovina, J. J., Dunne, J. P., Woodworth, P. A. \& Howell, E. A. Projected expansion of the subtropical biome and contraction of the temperate and equatorial upwelling biomes in the North Pacific under global warming. ICES J. Mar. Sci. (2011). doi:10.1093/icesjms/fsq198

45. Flombaum, P., Wang, W. L., Primeau, F. W. \& Martiny, A. C. Global picophytoplankton niche partitioning predicts overall positive response to ocean warming. Nat. Geosci. (2020). doi:10.1038/s41561-019-0524-2

46. Iudicone, D. Some may like it hot. Nature Geoscience (2020). doi:10.1038/s41561-020-0535-

47. Gorsky, G. et al. Expanding Tara Oceans Protocols for Underway, Ecosystemic Sampling of the Ocean-Atmosphere Interface During Tara Pacific Expedition (2016-2018). Front. Mar. Sci. (2019). doi:10.3389/fmars.2019.00750

48. Istace, B. et al. de novo assembly and population genomic survey of natural yeast isolates

49. Busseni, G. et al. Meta-Omics Reveals Genetic Flexibility of Diatom Nitrogen Transporters in Response to Environmental Changes. Mol. Biol. Evol. (2019). doi:10.1093/molbev/msz157

with the Oxford Nanopore MinION sequencer. Gigascience (2017). doi:10.1093/gigascience/giw018

\section{Acknowledgments}

406 PF was supported by a CFR doctoral fellowship and the NEOGEN impulsion grant from the 407 Direction de la recherche fondamentale (DRF) of the CEA. We thank the LSCE (Laboratoire 408 des sciences du climat et de l'environnement, CEA) for providing Earth System Models 409 outputs, Tilla Roy for preparation of the data, LAGE (Laboratoire d'Analyses Génomiques 
410 des Eucaryotes, CEA) members for stimulating discussions on this project, Mahendra

411 Mariadassou, Sakina Dorothée Ayata and Bruno Hay Mele for discussions on statistics and

412 climate envelop models, Laurent Bopp for initial discussions on this project and on climate

413 models, Tom Delmont for providing Metagenome-Assembled Genomes data and Noan Le

414 Bescot (TernogDesign) for artwork on Figures. We thank all members of the Tara Oceans

415 consortium for maintaining a creative environment and for their constructive criticism.

416 Tara Oceans would not exist without the Tara Ocean Foundation and the continuous

417 support of 23 institutes (https://oceans.taraexpeditions.org/).

418 This article is contribution number XX of Tara Oceans.

\section{Competing interests}

420 The authors declare no competing interests.

421 Author contributions

422 PF, OJ and MG conceived the study. MV wrote the bias correction algorithm. PF computed 423 the results, compiled and analyzed the data. PF wrote the initial draft of the paper. JL, OJ 424 and MG conducted a preliminary study. PF, OJ, MG, MV, DI, and PW discussed the results 425 and contributed to write the paper.

426 Online content

427 Supplementary information, additional references, source data and codes are available at 428 www.doi.xx.com/

\section{Materials and methods}

\section{Genomic provinces of plankton}

431 Environmental niches are computed for trans-kingdom plankton genomic provinces from 432 Richter et al. ${ }^{12}$. They consist of the clustering of metagenomic dissimilarity matrices from 6 433 available size fractions with sufficient metagenomic data from the Tara Oceans dataset. The 434 six size fractions (0-0.2, 0.22-3, 0.8-5, 5-20, 20-180 and 180-2000 $\mu \mathrm{m})$ represent major plankton groups. Two large size classes (180-2000 $\mu \mathrm{m}$ and 20-180 $\mu \mathrm{m})$ are enriched in zooplankton dominated by arthropods (mainly copepods) and cnidarians. They are expected to directly depend on smaller eukaryotes as they feed on them. Size classes 5-20 $\mu \mathrm{m}$ and 0.8-5 $\mu \mathrm{m}$ are enriched in smaller eukaryotic algae, such as dynophytes (5-20 $\mu \mathrm{m})$, 
pelagophytes and haptophytes $(0.8-5 \mu \mathrm{m})$. The distribution of these photoautotrophs presumably depends on nutrient availability. Finally, size classes 0.22-3 $\mu \mathrm{m}$ and 0-0.2 $\mu \mathrm{m}$ are respectively enriched in bacteria and viruses. Bacteria are characterized by a wide range of trophisms including autotrophy (cyanobacteria), mixotrophy and heterotrophy, while viruses are mainly parasites. Within each size fraction (from large to small), there are respectively 8, 8, 11, 6, 6 and 8 (48 in total) provinces defined in Richter et al. ${ }^{12}$ formed by Tara Oceans metagenomes (644 metagenomes sampled either at the surface (SUR) or at the Deep Chlorophyll Maximum (DCM) across 102 sites). The clustering of individual size fractions is independent.

\section{Genome signature of the provinces}

We analyzed the distribution of 713 eukaryotic and 523 prokaryotic genomes ${ }^{37,38}$ within the genomic provinces. These genomes are Metagenome-Assembled Genomes (MAGs) obtained from Tara Oceans metagenomes. For each size class, we select MAGs that are present (according to a criteria defined in Delmont et al. ${ }^{38}$ ) in at least 5 samples. We computed an index of presence enrichment of MAGs within provinces as the Jaccard index ${ }^{51}$, defined as follows:

$M_{11}$ is the number of samples where the MAG is present and match a sample of the province. $M_{01}$ and $M_{10}$ are respectively the number of samples where the MAG is not present in a sample of the province and inversely. A MAG is considered to be signature of a province if the Jaccard index is superior to 0.5 with this province and inferior to 0.1 for all other provinces of the given size class (Fig. 1 and Supplementary Fig. 3).

\section{World Ocean Atlas data}

Physicochemical parameters proposed to have an impact on plankton genomic provinces ${ }^{12}$ are used to define environmental niches: sea surface temperature (SST), salinity (Sal); dissolved silica $(\mathrm{Si})$, nitrate $\left(\mathrm{NO}_{3}\right)$, phosphate $\left(\mathrm{PO}_{4}\right)$, iron $(\mathrm{Fe})$, and a seasonality index of nitrate $\left(\mathrm{SI} \mathrm{NO}_{3}\right)$. With the exception of $\mathrm{Fe}$ and $\mathrm{SI} \mathrm{NO}_{3}$, these parameters are extracted from the gridded World Ocean Atlas 2013 (WOA13) ${ }^{39}$. Climatological Fe fields are provided by the biogeochemical model PISCES-v252. The seasonality index of nitrate is defined as the 
range of nitrate concentration in one grid cell divided by the maximum range encountered in WOA13 at the Tara Oceans sampling stations. All parameters are co-located with the corresponding stations and extracted at the month corresponding to the Tara Oceans sampling. To compensate for missing physicochemical samples in the Tara Oceans in situ data set, climatological data (WOA) are preferred. The correlation between in situ samples and corresponding values extracted from WOA are high ( $\mathrm{r}^{2}$ : SST: 0.96, Sal: 0.83, Si: 0.97, $\mathrm{NO}_{3}: 0.83, \mathrm{PO}_{4}: 0.89$ ). In the absence of corresponding WOA data, a search is done within $2^{\circ}$ around the sampling location and values found within this square are averaged.

Nutrients, such as $\mathrm{NO}_{3}$ and $\mathrm{PO}_{4}$, display a strong collinearity when averaged over the global ocean (correlation of 0.95 in WOA13) which could complicate disentangling their respective contributions to niche definition. However, observations and experimental data allow identification of limiting nutrients at regional scale characterized by specific plankton communities ${ }^{53}$. The projection of niches into future climate would yield spurious results when the present-day collinearity is not maintained ${ }^{54}$ but there is up to now no evidence for large scale changes in global nutrient stoichiometry ${ }^{55}$.

\section{Earth System Models and bias correction}

Outputs from 6 Earth System Models (ESM) (Supplementary Table 2) are used to project environmental niches under greenhouse gas emission scenario RCP8.5 ${ }^{42}$. Environmental drivers are extracted for present day (2006-2015) and end of century (2090-2099) conditions for each model and the multi-model mean is computed. A bias correction method, the Cumulative Distribution Function transform, CDFt ${ }^{56}$, is applied to adjust the distributions of SST, Sal, $\mathrm{Si}, \mathrm{NO}_{3}$ and $\mathrm{PO}_{4}$ of the multi-model mean to the WOA database. CDFt is based on a quantile mapping (QM) approach to reduce the bias between modeled and observed data, while accounting for climate change. Therefore, CDFt does not rely on the stationarity hypothesis and present and future distributions can be different. CDFt is applied on the global fields of the mean model simulations. By construction, CDFt preserves the ranks of the simulations to be corrected. Thus, the spatial structures of the model fields are preserved.

\section{Environmental niche models: training, validation and projections}


Provinces with similar metagenomic content are retrieved from Richter et al. ${ }^{12}$. From a total of 48 initial provinces, 10 provinces are removed either because they are represented by too few samples ( 7 out of 10) or they are found in environments not resolved by ESMs (e.g. lagoons of Pacific Ocean islands, 3 out of 10). Four machine learning methods are applied to compute environmental niches for each of the 38 provinces: Gradient Boosting Machine (gbm) ${ }^{57}$, Random Forest (rf) ${ }^{58}$, fully connected Neural Networks (nn) ${ }^{59}$ and Generalized Additive Models (gam) ${ }^{60}$. Hyper parameters of each technique (except gam) are optimized. These are (1) for gbm, the interaction depth (1, 3 and 5), learning rate (0.01, 0.001 ) and the minimum number of observations in a tree node (1 to 10); (2) for rf, the number of trees (100 to 900 with step 200 and 1000 to 9000 with step 2000) and the number of parameters used for each tree (1 to 7); (3) for nn, the number of layers of the network (1 to 10 ) and the decay $\left(1.10^{-4}\right.$ to $9.10^{-4}$ and $1.10^{-5}$ to $9.10^{-5}$ ). For gam the number of splines is set to 3, respectively 2 only when not enough points are available (for fraction 0-0.2, 65 points). R packages gbm (2.1.3), randomForest (4.6.14), mgcv (1.8.16) and nnet (7.3.12) are used for gbm, rf, nn and gam models.

To define the best combination of hyper parameters for each model, we perform 30 random cross-validations by training the model on 75\% (85 \% for gbm and gam) of the dataset randomly sampled and by calculating the Area Under the Curve ${ }^{61}$ (AUC) on the $25 \%$ (15\% for gbm and gam) remaining points of the dataset. The best combination of hyper parameters is the one for which the mean AUC over the 30 cross-validation is the highest. A model is considered valid if at least 3 out of the 4 techniques have a mean AUC superior to 0.65 , which is the case for 27 out of the 38 provinces (Supplementary Fig. 2a). A climatic annotation is given to the 27 validated niches (Supplementary Table 1). Final models are trained on the full dataset and only the techniques that have a mean AUC higher than 0.65 are considered to make the projections. The majority (23) of the 27 validated niches is validated by all four models and 4 by only 3 models. Relative influences of each 523 parameter in defining environmental niches are calculated using the feature_importance 524 function from the DALEX R package ${ }^{62}$ for all four statistical methods (Supplementary Fig. 525 19a). To evaluate the consistency and coherence of environmental niche models, we first 526 make global projections on the 2006-13 WOA2013 climatology. Projections are consistent with sampling regions for provinces encompassing vast oceanic areas. For example, the 
genomic province sampled in temperate Atlantic regions of size fraction $180-2000 \mu \mathrm{m}$ is projected to be present in the north and south temperate Atlantic but also other temperate regions (Supplementary Fig. 4). For model training and projections, physicochemical variables are scaled to have a mean of 0 and a variance of 1 . For this scaling, the mean and standard deviation of each WOA13 variable (+ PISCES-v2 Fe) co-localized with Tara Oceans stations with a value available are used. This standardization procedure allows for better performance of nn models. Finally, as statistical models often disagree on projection sets whereas they give similar predictions on the training set (Supplementary Fig. 5, 6), we use the ensemble model approach for global-scale projections of provinces ${ }^{36}$ i.e. the mean projections of the validated machine learning techniques.

\section{Combined size classes provinces and ocean partitioning comparisons}

To combine all size classes' provinces, we use the PHATE algorithm ${ }^{41,63}$ from R package phateR. This algorithm allows visualization of high dimensional data in the requested number of dimensions while best preserving the global data structure ${ }^{63}$. We choose to train PHATE separately on WOA13 projections and present day and end of century projections including presence probabilities of non dominant provinces. We use 3 dimensions and set hyper parameter k-nearest neighbors (knn) and decay respectively to 1000 for WOA13 and 2000 for model data as in this case there are twice as many points. The hyper parameter knn reflects the degree to which the mapping of PHATE from high to low dimensionality should respect the global features of the data. We argue that 1000 and 2000 are good choices as it will be sufficient to have a highly connected graph, conserve global structure, allow visualization of structures of the size of the provinces (mean number of points in a province: 4867) and have a reasonable computational time. Decay is set to 20 in both cases. Then we cluster the resulting distance matrix using the k-medoïds algorithm ${ }^{64}$ and the silhouette average width criteria 65 is used as an indicator of good fit. The silhouette criterion is maximal for 2, 3 and 4 clusters and 2 peaks are found at 7 and 14 clusters (the peak at 7 is slightly less high than the one at 14, data not shown). We choose to present the 4 and 7 clusters geographical patterns as they seem more relevant with respect to the resolutions of our environmental datasets (WOA13 and climate models). We compare the three polar clusters of the 7 cluster geographical patterns with Antarctic Circumpolar Currents fronts ${ }^{66}$ by overlying them on the map (red lines Fig. $2 \mathrm{~h}$ ). 
To visualize the global biogeography structure, the resulting 3 vectors of PHATE are plotted using an RGB color code. Each coordinate of each vector is respectively assigned to a given degree of color component between 0 and 255 ( 8 bits red, green or blue) using the following formula (Fig. 1 g,h; Fig 2 e,f; Supplementary Fig. 7):

$$
C_{-} \operatorname{col}(i)=\frac{C(i)-\min (C(1), C(2), C(3))}{\max (C(1), C(2), C(3))-\min (C(1), C(2), C(3))} * 255
$$

$C(i)$ is the ith component of the PHATE axes. Respectively, components 1,2 and 3 are assigned to red, green and blue.

To compare the six size fraction provinces, the combined size class with existing biogeochemical partitions of the oceans ${ }^{10,11}$ and with each other, we use the adjusted rand index $^{67}$ (Supplementary Fig. 7-9) and overlay their masks above our partitions. In this case, presence probabilities of dominant provinces are not used anymore. Instead, each ocean grid point is assigned to the dominant provinces or the phate clusters.

\section{Bray-Curtis dissimilarity index}

Climate change impact on global projections is calculated at each grid point as the BrayCurtis dissimilarity index ${ }^{68,69}$ defined as follows:

$$
B C=\frac{\sum_{n}\left|P_{n}^{\text {future }}-P_{n}^{\text {present }}\right|}{\sum_{n}\left|P_{n}^{\text {future }}+P_{n}^{\text {present }}\right|}
$$

Where $\left(P_{n}^{\text {present }}\right.$ and $\left.P_{n}^{\text {future }}\right)$ are respectively the probability of presence of the province $\mathrm{n}$ in present day and at the end of the century. Only the probabilities of dominant provinces are non-null and all others are set to zero. The mask of main fisheries ${ }^{70}$ (chosen as the first 4 deciles) and Exclusive Economical Zones ${ }^{71}$ is overlaid on the Bray-Curtis map.

\section{Change in province assemblages}

A province assemblage is defined as the assemblage of dominant provinces of each size fraction at a given grid point of the considered ocean. We consider two criteria of change in province assemblage between present day and end of the century conditions. The first one, more straightforward and less stringent, considers that a province assemblage occurs when a change of dominant province is found in at least one size fraction. In a more stringent way, a change of assemblage is considered significant for $B C>\frac{1}{6}$ (previous section). This threshold corresponds to an idealized case where each dominant province 
587 has a probability of one and a change of dominant province is found in only one size 588 fraction. For example, the dominant province assemblage goes from vector

589

590

591

592

593

594

595

596

597

598

599

600

601

602

603

604

605

606

607

608

609

610

611

612

613

614

615 (F5,E6,D3,C8,B7,A7) (with the size fractions in decreasing order) corresponding to all temperate provinces to vector (F8,E6,D3,C8,B7,A7). This example corresponds to the replacement of the temperate province of size fraction 180-2000 $\mu \mathrm{m}$ (F5) by the tropicoequatorial province (F8). This criterion allows us to discard assemblage changes for which the changes in probability of presence of dominant provinces are very low. With this criterion, only on a small oceanic area is found to have no changes of assemblage (Fig. 4c light blue zones).

\section{Centroids and migration shifts}

The centroid of each province is defined as the average latitude and longitude for which the probability of presence is superior to 0.5 and weighted by both the probability of presence at each grid point and the grid cell area. It is calculated for both present day conditions and end of the century conditions. The migration shift is calculated as the distance between the present day and the end of the century centroids considering the earth as a perfect sphere of radius $6371 \mathrm{~km}$. For consistency (i.e. avoid long distance aberrant shifts), it is only calculated for provinces with an area of dominance larger than $10^{6} \mathrm{~km}^{2}$ in the given basin.

\section{Driver analysis}

To assess the relative importance of each driver in province changes, the methodology from Barton et al. ${ }^{24}$ is adopted. For a set $\mathrm{N}$ of $\mathrm{n}$ provinces (individual provinces or all provinces together), the probability of presence of each province is recalculated for present day conditions except for driver $d$ (from the set of drivers D) for which end of the century condition is used $\left(P_{n}^{\text {future for dth driver only }}\right)$. The set of driver D can be either all drivers (Fig. 5a,c) or all drivers except SST (Fig. 5b). The relative importance of driver $d$ at a given grid point for the set $\mathrm{N}$ of provinces is computed as follow:

$$
R I(d)=\frac{\sum_{n \in N}\left|P_{n}^{\text {future for dth driver only }}-P_{n}^{\text {present }}\right|}{\sum_{d \in D} \sum_{n \in N}\left|P_{n}^{\text {future for dth driver only }}-P_{n}^{\text {present }}\right|}
$$

$R I(d)$ is computed at grid cells where $B C>\frac{1}{6}, B C$ being calculated with either the set of all drivers (Fig. 5a,c) or all drivers except SST (Fig. 5b). When RI(d) is calculated for individual provinces (Fig. 5c and Supplementary Fig. 16d,e), it is computed only at grid cells where 
$616 B C>\frac{1}{6}$ and the concerned province is either dominant in present day and/or end of

617 century conditions.

618 References

619 51. Jaccard, P. Distribution comparée de la flore alpine dans quelques régions des Alpes

620

621 occidentales et orientales. Bull. la Murithienne (1902).

622

623

624

52. Aumont, O., Ethé, C., Tagliabue, A., Bopp, L. \& Gehlen, M. PISCES-v2: An ocean biogeochemical model for carbon and ecosystem studies. Geosci. Model Dev. (2015). doi:10.5194/gmd-82465-2015

53. Moore, C. M. et al. Processes and patterns of oceanic nutrient limitation. Nature Geoscience (2013). doi:10.1038/ngeo1765

54. Brun, P., Kiørboe, T., Licandro, P. \& Payne, M. R. The predictive skill of species distribution models for plankton in a changing climate. Glob. Chang. Biol. (2016). doi:10.1111/gcb.13274

55. Redfield, A. C. On the Proportions of Organic Derivatives in Sea Water and Their Relation to the Composition of Plankton. in James Johnstone Memorial Volume 1767-192 (Liverpool Univ. Press, Liverpool, U.K., 1934).

632

56. Michelangeli, P. A., Vrac, M. \& Loukos, H. Probabilistic downscaling approaches: Application to wind cumulative distribution functions. Geophys. Res. Lett. (2009). doi:10.1029/2009GL038401

57. Ridgeway, G. gbm: Generalized Boosted Regression Models. R Packag. version 1.6-3.1 (2010).

58. Breiman, L. \& Cutler, A. Breiman and Cutler's random forests for classification and regression. Packag. 'randomForest' (2012). doi:10.5244/C.22.54

59. Venables, W. N. \& Ripley, B. D. Modern Applied Statistics with S Fourth edition by. World (2002). doi:10.2307/2685660

60. Wood, S. N. Stable and efficient multiple smoothing parameter estimation for generalized additive models. J. Am. Stat. Assoc. (2004). doi:10.1198/016214504000000980

61. Fawcett, T. An introduction to ROC analysis. Pattern Recognit. Lett. (2006). doi:10.1016/j.patrec.2005.10.010

62. Biecek, P. DALEX: explainers for complex predictive models. J. Mach. Learn. Res. 19, 1-5 (2018).

63. Vallejos, C. A. Exploring a world of a thousand dimensions. Nature Biotechnology (2019). doi:10.1038/s41587-019-0330-9

64. L., K. \& P., R. Clustering by means of Medoids. in Statistical Data Analysis Based on the L1 Norm and Related Methods (1987). 
649 65. Rousseeuw, P. J. Silhouettes: A graphical aid to the interpretation and validation of cluster

650 analysis. J. Comput. Appl. Math. (1987). doi:10.1016/0377-0427(87)90125-7

651 66. Orsi, A. H., Whitworth, T. \& Nowlin, W. D. On the meridional extent and fronts of the Antarctic 652 Circumpolar Current. Deep. Res. Part I (1995). doi:10.1016/0967-0637(95)00021-W

653 67. Hubert, L. \& Arabie, P. Comparing partitions. J. Classif. (1985). doi:10.1007/BF01908075

654 68. Somerfield, P. J. Identification of the Bray-Curtis similarity index: Comment on Yoshioka 655 (2008). Marine Ecology Progress Series (2008). doi:10.3354/meps07841

656 69. Bloom, S. Similarity Indices in Community Studies: Potential Pitfalls. Mar. Ecol. Prog. Ser. (1981). doi:10.3354/meps005125

658 70. Watson, R. A. A database of global marine commercial, small-scale, illegal and unreported fisheries catch 1950-2014. Sci. Data (2017). doi:10.1038/sdata.2017.39

660 71. Flanders Marine Institute (2018). Maritime Boundaries Geodatabase: Maritime Boundaries and Exclusive Economic doi:https://doi.org/10.14284/313. 


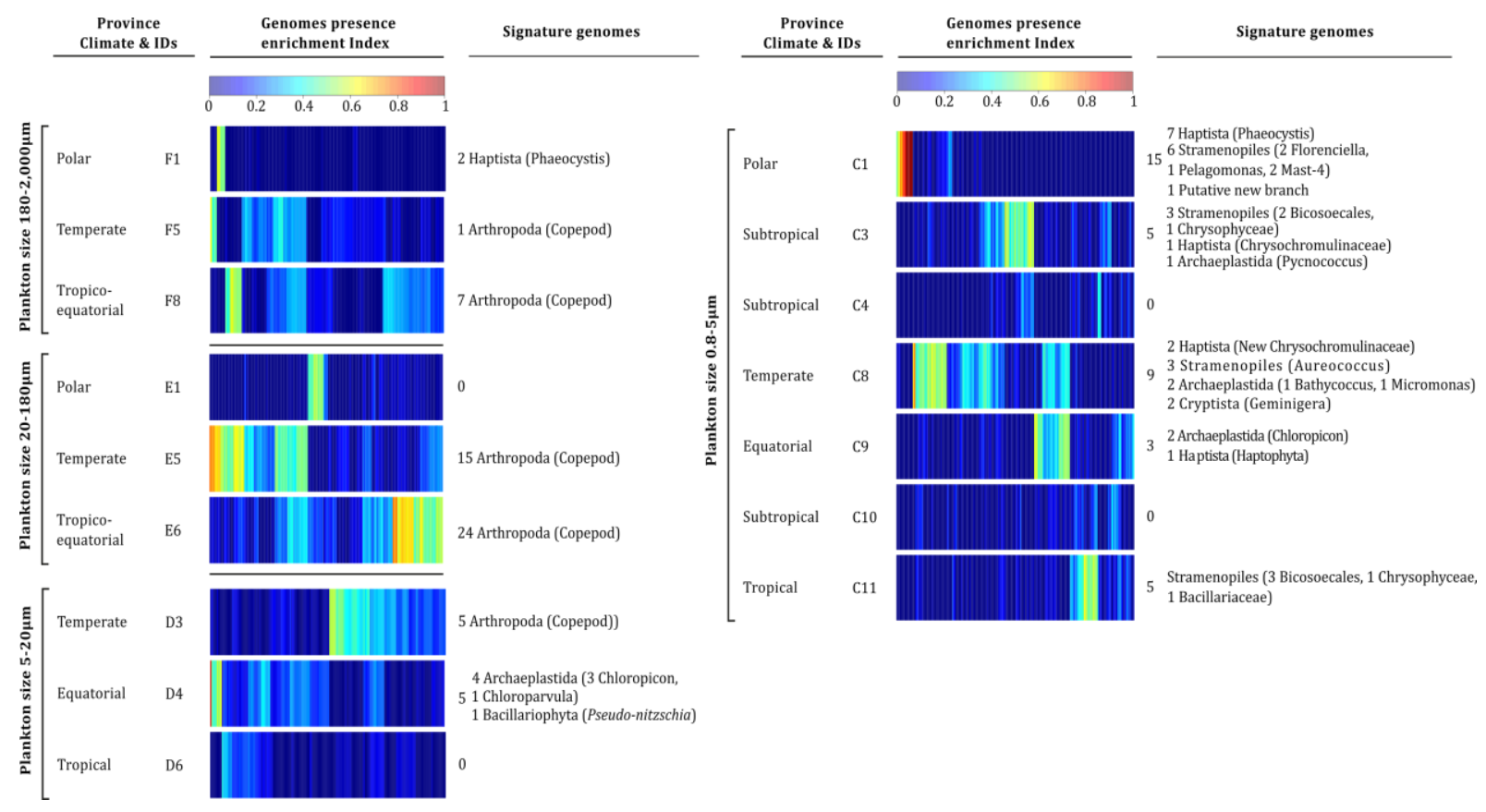

665 Fig. 1 | Signature genomes of provinces of eukaryotes enriched size classes. For each plankton

666 size class, indexes of presence enrichment for 713 genomes of eukaryotic plankton ${ }^{38}$ in 667 corresponding provinces are clustered and represented in a color scale. Signature genomes 668 (see Methods) are found for almost all provinces, their number and taxonomies are summarized 669 (detailed list in Supplementary Table 6). 
a

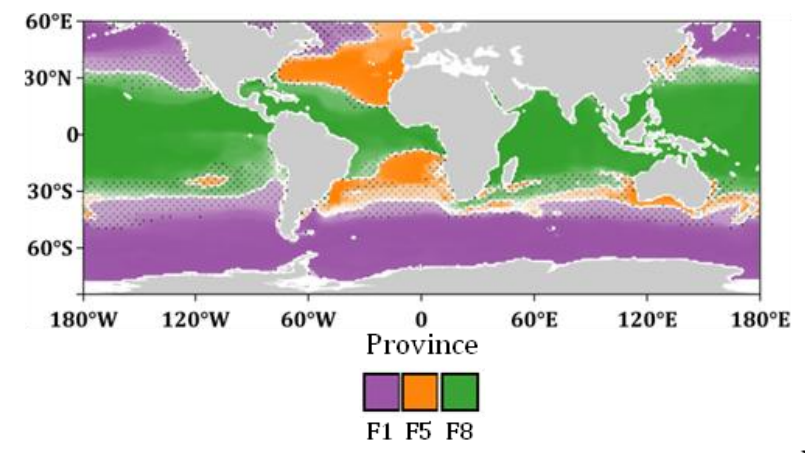

c

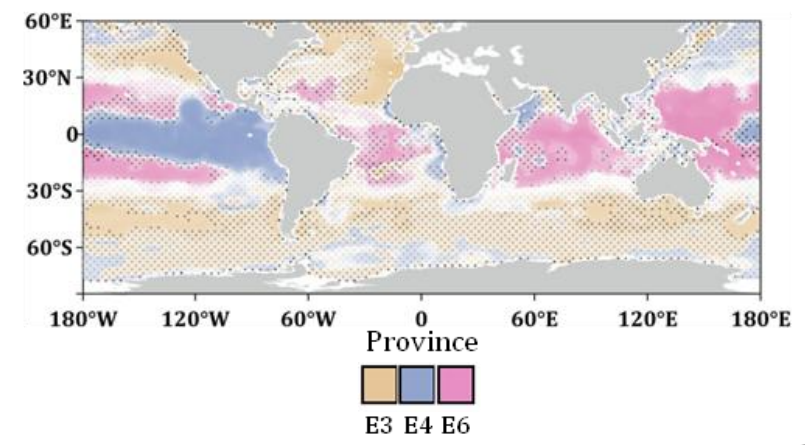

e

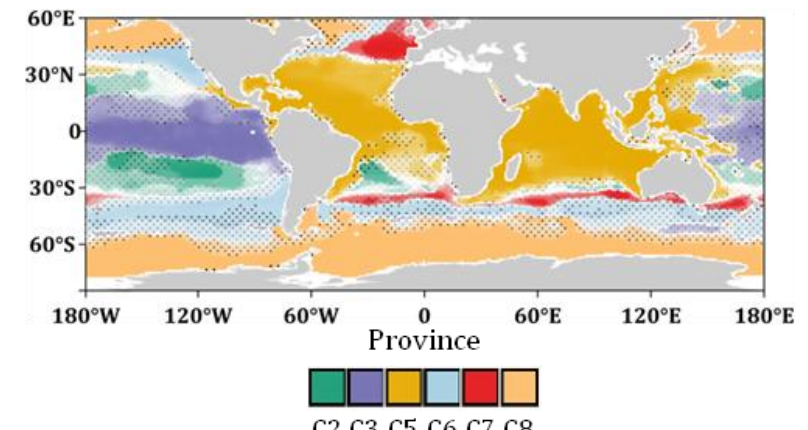

g

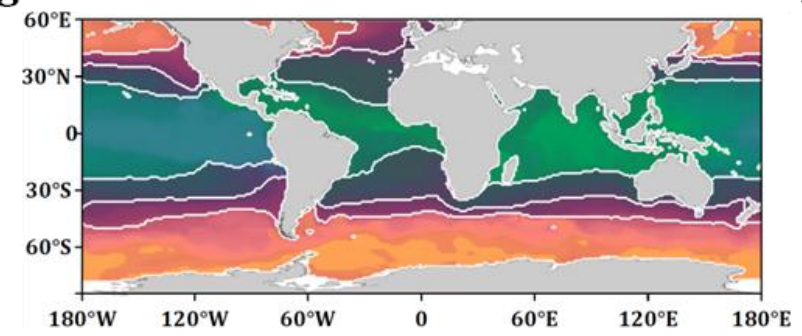

b

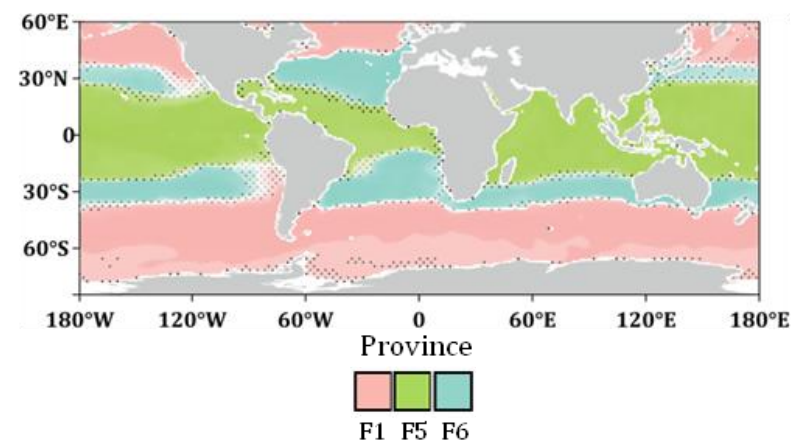

d

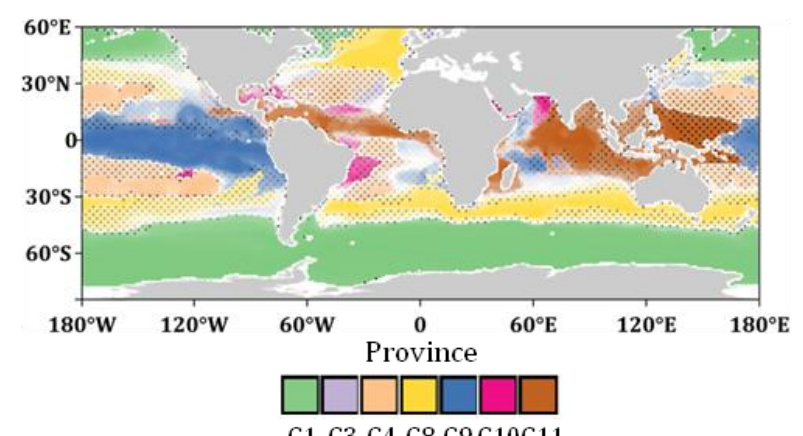

f

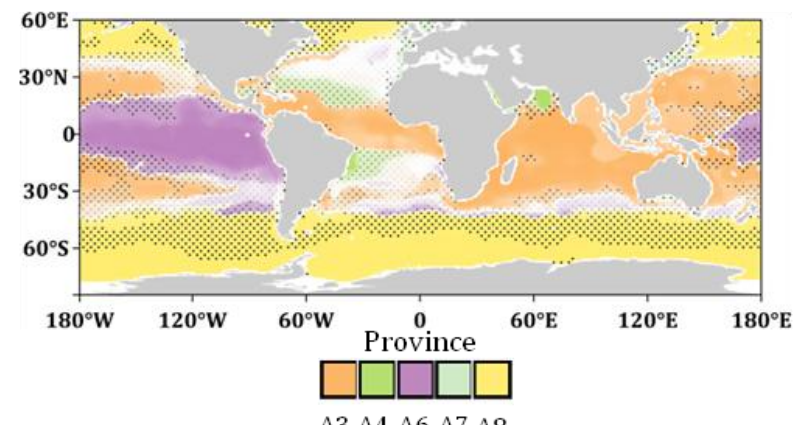

h

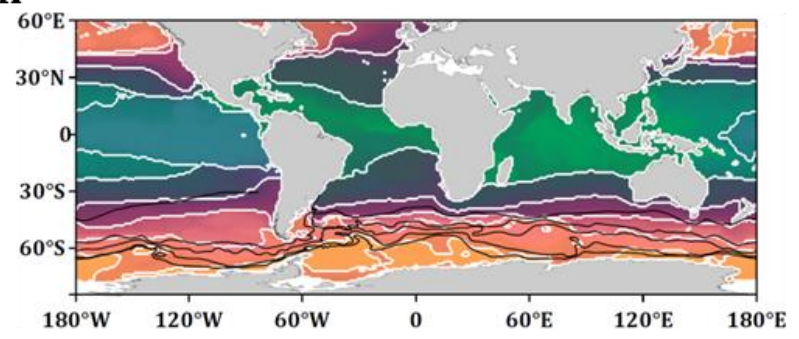

671 Fig. 2 | Global biogeographies of size-structured plankton provinces projected on W0A2013

672 dataset. (a) Metazoans enriched (180-2000 $\mu \mathrm{m})$ (b) Small metazoans enriched (20-180 $\mu \mathrm{m})(\mathbf{c})$

673 Small eukaryotes enriched (5-20 $\mu \mathrm{m})$ (d) Small eukaryotes enriched (0.8-5 $\mu \mathrm{m})$ (e) Bacteria

674 enriched (0.22-3 $\mu \mathrm{m}$ ) (f) Viruses enriched (0-0.2 $\mu \mathrm{m})$. (a-f) Dotted areas represent uncertainty

675 areas where the delta of presence probability of the dominant province and an other (from the

676 same size fraction) is inferior to 0.5. (g) Combined size class biogeography using PHATE algorithm 
677 partitioned in 4 clusters. Areas of uncertainty are highlighted with dotted lines. (h) Combined size

678 class biogeography using PHATE algorithm partitioned in 7 clusters overlaid with Antarctic

679 Circumpolar Current boundaries (red). Simple biogeographies are observed in large size fractions

$680(>20 \mu \mathrm{m})$ with a partitioning in three major oceanic areas: tropico-equatorial, temperate and polar.

681 More complex geographic patterns and patchiness are observed in smaller size fractions with the

682 distinction of pacific equatorial provinces and provinces associated to oligotrophic tropical gyres. 
a

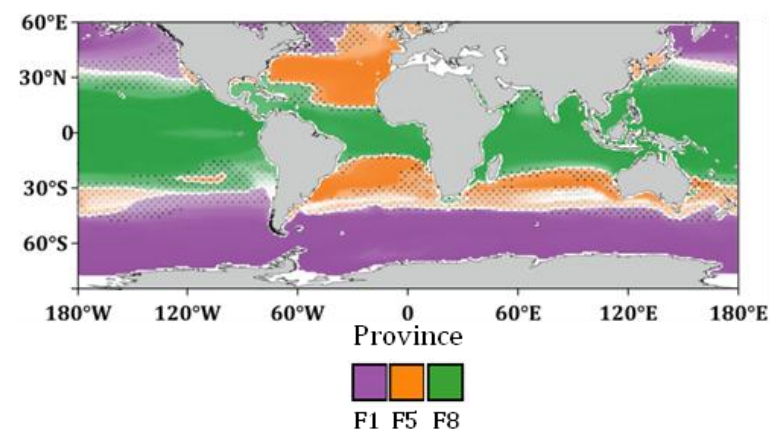

c

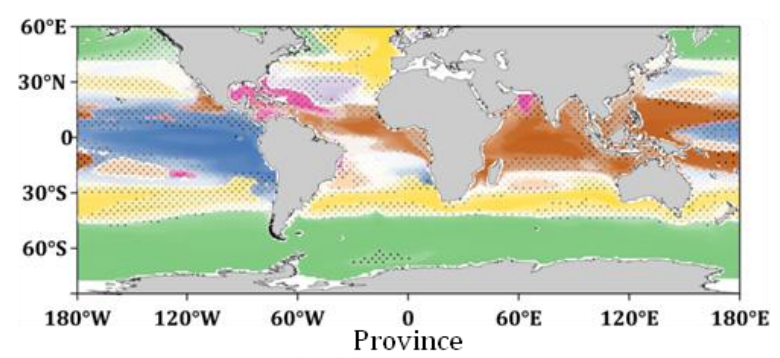

e

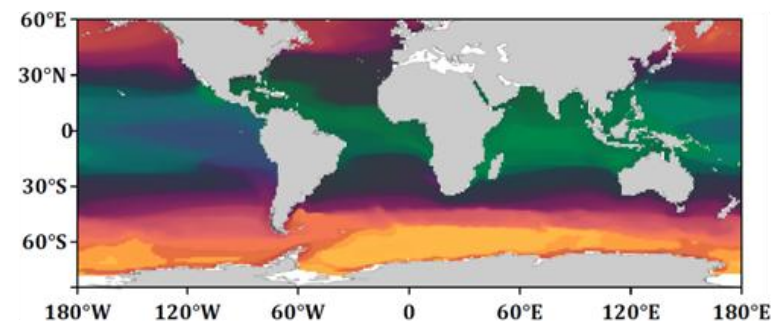

b

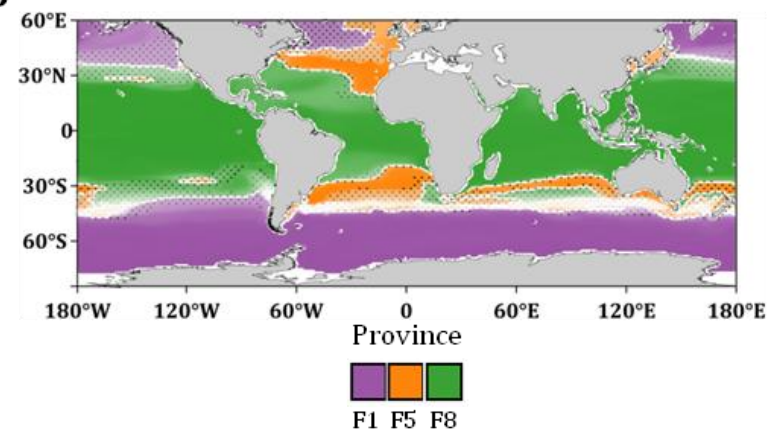

d

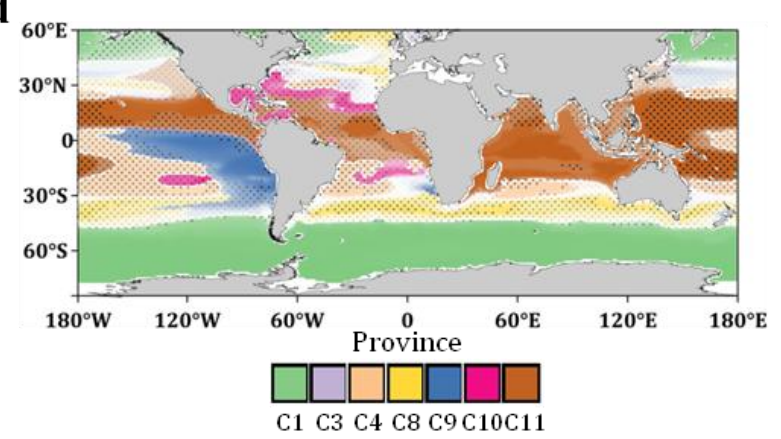

f

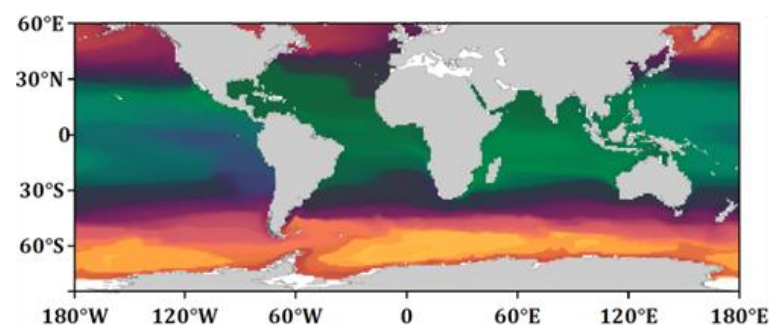

Fig. 3 | Global biogeography of small metazoans enriched size fraction (180-2000 $\mu \mathrm{m})$, protists enriched (0.8-5 $\mu \mathrm{m})$ and combined size classes in modeled present day (a, c, e) and end of the century (b, d, f). (a-d)The dominant niche i.e. the one predicted to have the highest probability of presence is represented at each grid point of the map. The color transparency is the probability of presence of the dominant niche. A simple biogeography is observed for size fraction $180-2000 \mu \mathrm{m}(\mathbf{a}, \mathbf{b})$ with a polar niche, a temperate and a tropico-equatorial niche. Biogeography of size fraction 0.8-5 $\mu \mathrm{m}$ size fraction is more complex and patchy with several temperate and tropical niches (c, d). Biogeography of large size plankton and small size plankton are therefore decoupled. Climate change impacts tropical niches which are expanding towards the poles in both size fractions with a more complex behavior in size fraction 0.8-5 $\mu \mathrm{m}$ (b and d). (e, f) Present and end of century combined size classes using PHATE algorithm. 
bioRxiv preprint doi: https://doi.org/10.1101/2020.10.20.347237; this version posted November 24,2020 . The copyright holder for this preprint (which was not certified by peer review) is the author/funder, who has granted bioRxiv a license to display the preprint in perpetuity. It is made available under aCC-BY-NC-ND 4.0 International license.

696

\begin{tabular}{|c|c|c|c|c|c|c|c|}
\hline $\begin{array}{c}\text { Size } \\
\text { fraction } \\
(\mu \mathrm{m})\end{array}$ & $\begin{array}{c}\text { Present } \\
\text { day } \\
\text { covered } \\
\text { area (\%) }\end{array}$ & $\begin{array}{c}\text { End of } \\
\text { century } \\
\text { covered } \\
\text { area (\%) }\end{array}$ & $\begin{array}{c}\% \text { area with a } \\
\text { change of } \\
\text { dominant } \\
\text { province }\end{array}$ & Most frequent transition & $\%$ & $2^{\text {nd }}$ most frequent transition & $\%$ \\
\hline $180-2000$ & 74 & 74 & 13 & $\begin{array}{c}\text { temperate->tropico- } \\
\text { equatorial } \\
(5->8)\end{array}$ & 67 & $\begin{array}{c}\text { polar->temperate } \\
\qquad(1->5)\end{array}$ & 14 \\
\hline $20-180$ & 78 & 77 & 12 & $\begin{array}{c}\text { temperate->tropico- } \\
\text { equatorial } \\
(6->5)\end{array}$ & 67 & $\begin{array}{c}\text { polar->temperate } \\
\qquad(1->6)\end{array}$ & 29 \\
\hline $5-20$ & 45 & 49 & 22 & $\begin{array}{c}\text { temperate } \\
\text {-> equatorial } \\
(3->4)\end{array}$ & 47 & $\begin{array}{c}\text { equatorial } \\
->\text { tropical } \\
(4->6)\end{array}$ & 25 \\
\hline $0.8-5$ & 56 & 59 & 31 & $\begin{array}{l}\text { equatorial }->\text { tropical } \\
\qquad(9->11)\end{array}$ & 22 & $\begin{array}{c}\text { temperate } \\
->\text { equatorial } \\
\quad(8->9)\end{array}$ & 15 \\
\hline $0.22-3$ & 60 & 61 & 15 & $\begin{array}{l}\text { temperate-> tropical } \\
(7->5)\end{array}$ & 22 & $\begin{array}{c}\text { polar }->\text { temperate } \\
(8->6)\end{array}$ & 16 \\
\hline $0-0.2$ & 64 & 66 & 16 & $\begin{array}{l}\text { equatorial }->\text { tropical } \\
\qquad(6->3)\end{array}$ & 32 & $\begin{array}{c}\text { temperate } \\
->\text { equatorial } \\
(8->6)\end{array}$ & 31 \\
\hline
\end{tabular}

697 Table 1 | Global statistics of covered areas and provinces' changes and transitions. From $12 \%$

698 to $31 \%$ of the total covered area is estimated to be replaced by a different province at the end of the 699 century compared to present day depending on the size fraction. In total, considering all size 700 fractions this represents $60 \%$ of the total covered area with at least one predicted change of 701 dominant province across the six size fractions. 


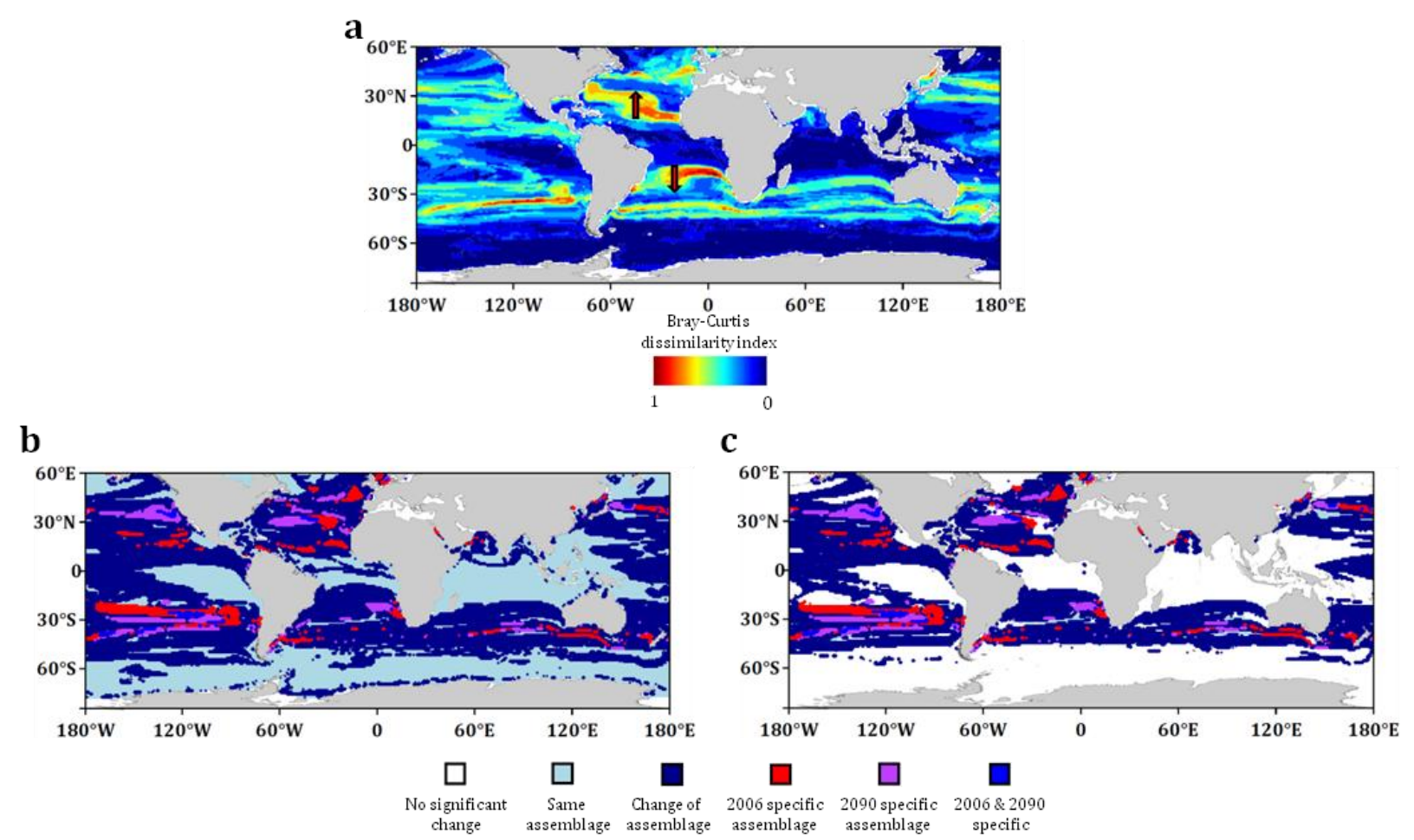

Fig. 4 | (a) Bray-Curtis dissimilarity index map comparing present day with end of the century projections of dominant provinces. Maps of trans-kingdom assemblages reorganization of dominant provinces (b) and with a criterion of significance (c). (a) BrayCurtis dissimilarity index is calculated by integrating all the dominant provinces presence probabilities over the six size fraction. Most important changes appear in subtropical, temperate and subpolar regions. These changes are due to the displacement of tropical and temperate provinces towards the pole but also the geographical decoupling between large and small size plankton. The mean change in niche dissimilarity index is 0.25. (b) An assemblage is the combined projected presence of the dominant province of each size class. Assemblage reorganization (present day versus end of the century) is either mapped on all considered oceans or with a criterion on the criterion from $60.1 \%$ (b, dark blue) to $48.7 \%$ (c, dark blue) of the oceanic area is projected to change of assemblage. New assemblage are expected to appear in 2090 (purple+blue) whereas some 2006 specific assemblages are projected to disappear (red+blue). New assemblages as well as lost assemblages are mostly found in temperate, subtropical and tropical regions where most of the rearrangements are projected. 
a

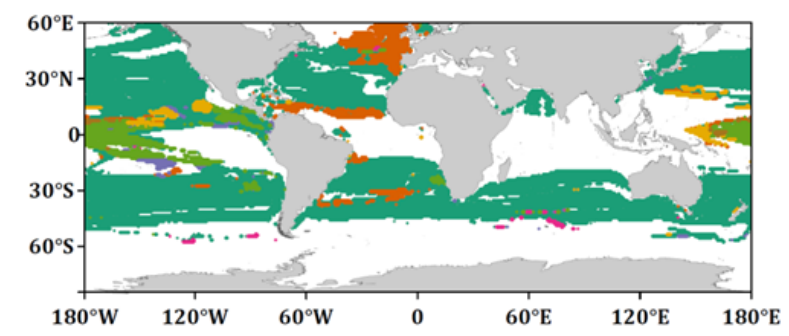

b

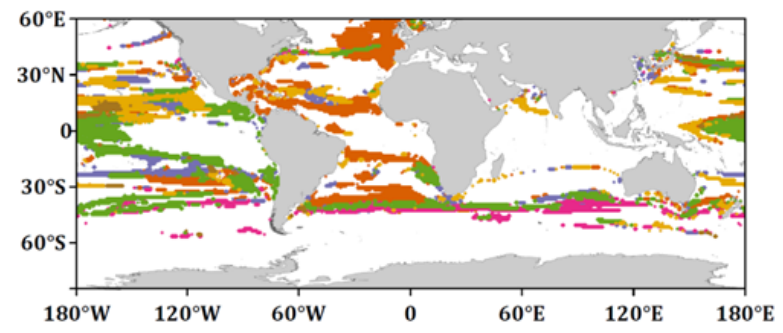

c

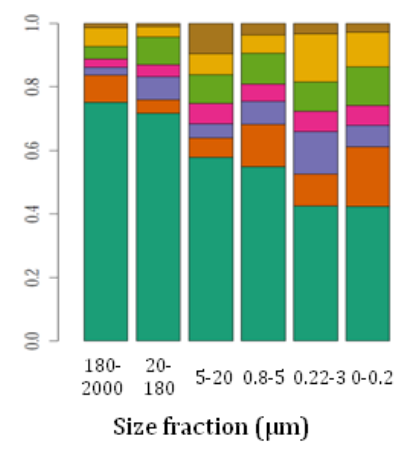

Driver

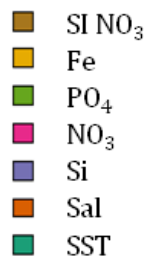

Fig. 5 | Map of most impacting drivers on dominant province changes (a), most impacting driver without considering temperature change (b) and relative importance of the drivers in

722 the different size fractions (c). (a) Temperature appears as the top impacting driver on the

723 majority of the projected ocean with a significant change of province (Fig. 4). (b) Salinity and

724 dissolved phosphate are found to be the second and third driver of province reorganization notably

725 at tropical and subpolar latitudes. Note the importance of nitrate at temperate southern latitudes.

726 (c) Temperature is found to be the most important driver for all size classes but has a more 727 important impact in large size classes $(>20 \mu \mathrm{m})$. Nutrients have on average a relative more important impact in small size classes in driving provinces reorganization. 


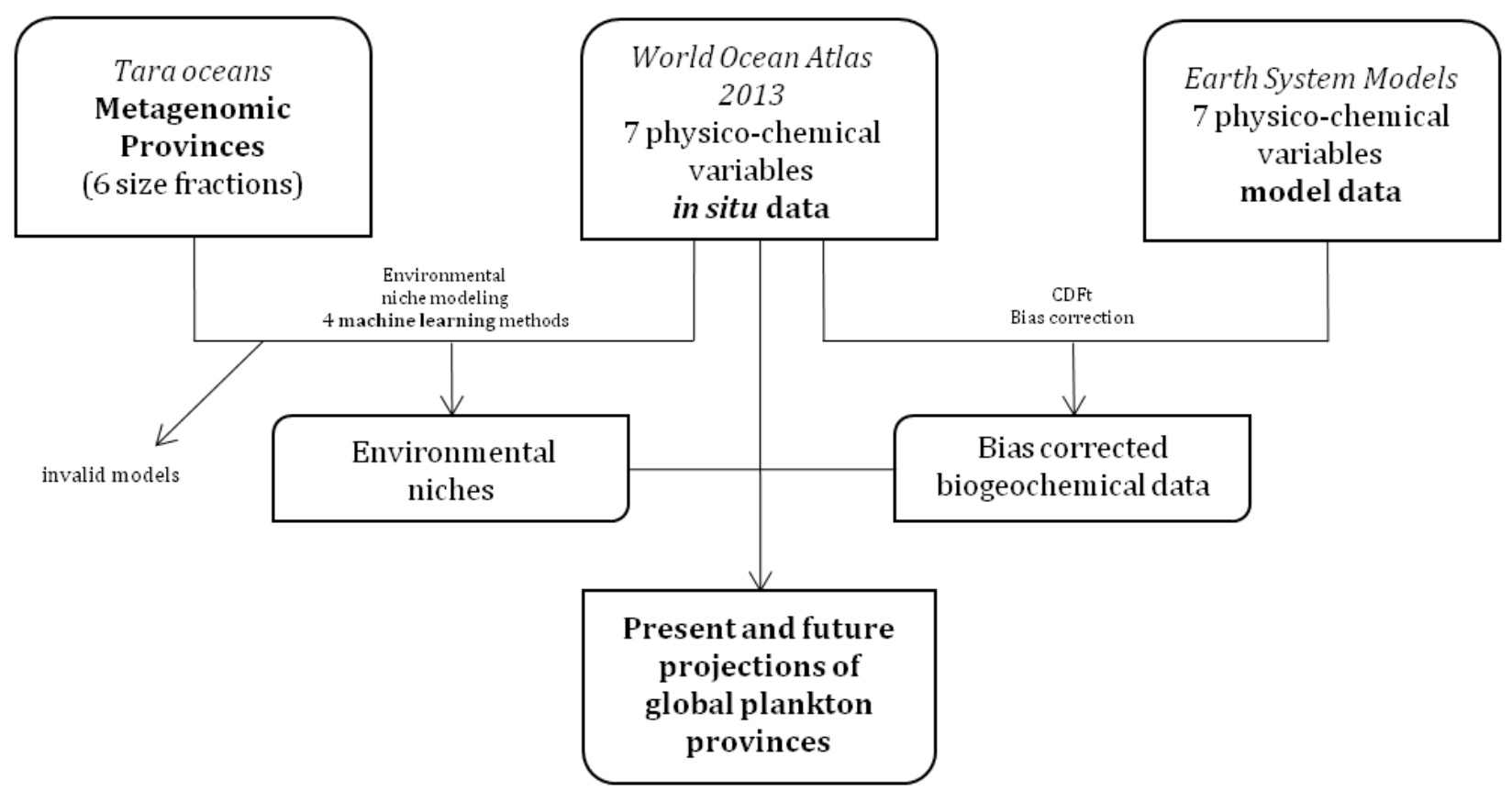
expedition and in situ measurements of physicochemical variables (World Ocean Atlas 2013, 732 WOA13) $^{1}$ are combined to define environmental niches at the plankton community level across 6 733 size fractions of the plankton realm. Bias corrected outputs from a mean model of 6 Earth System 734 Models $^{2-7}$ and WOA13 data are then used to project global plankton provinces for present day 735 conditions and end of the century conditions under a high emission climate change scenario 736 (RCP8.5) ${ }^{8}$. Physico-chemical variables are Sea Surface Temperature (SST), Salinity (Sal), Dissolved 737 silica (Si), Nitrate $\left(\mathrm{NO}_{3}\right)$, Phosphate (PO4), Iron (Fe) and a seasonality index of nitrate $\left(\mathrm{SI} \mathrm{NO}_{3}\right)$. 


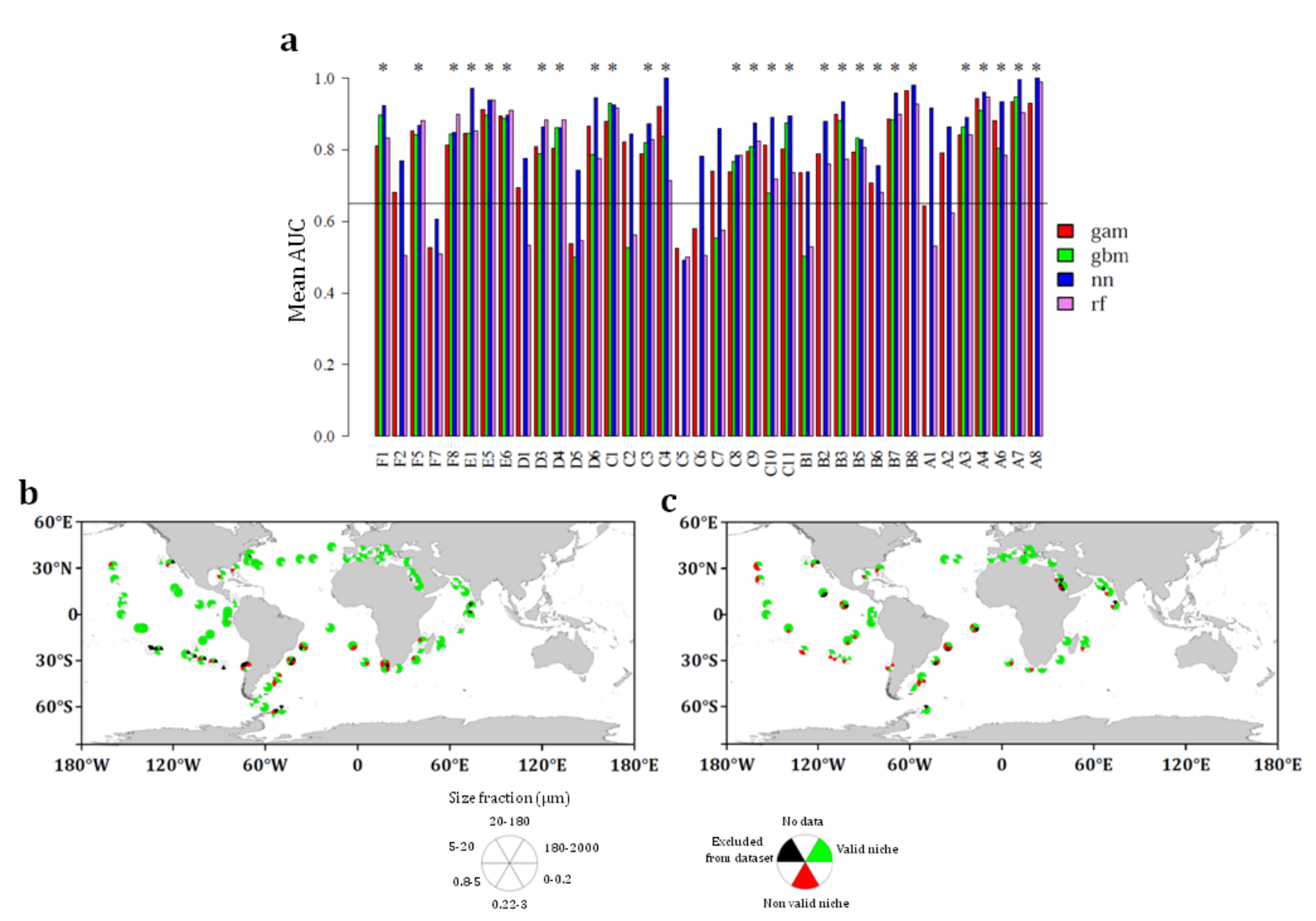
Supplementary Fig. 2 | (a) Barplot of mean AUC over 30-fold cross validation process of the 38 initial metagenomic provinces. (b,c) Map of validated and non validated stations across the six size fractions in surface samples (b) and DCM samples (c). (a) Mean AUC (Area Under the receiver operating Characteristic) ${ }^{9}$ is plotted for the best hyperparameter combination of the 4 machine learning techniques used for each of the 38 metagenomic provinces. General Additive Models $^{10}$ (gam) are shown in red (no optimization), Gradient Boosting Machines ${ }^{11}$ (gbm) in green, fully connected Neural Networks ${ }^{12}(\mathrm{nn})$ in blue and Random Forest ${ }^{13}$ models in purple (rf). A star for valid models is drawn at the top of each considered valid model. A model is validated when at least 3 out of the four models have a mean AUC superior to 0.65. A valid model is found for 27 out of 38 initial provinces. Out of the 27 validated models 4 are not valid for the gbm method. (b-c) For each Tara sample present in the dataset at surface (b) or Deep Chlorophyll Maximum (DCM) (c) and for each size fraction, the filter (one size fraction at one location and one depth) belongs either to a validated niche (green), a non validated niche (red), an excluded filter (sea Materials \& Methods) (black) or no data is available (white). Non validated niches represent only $11 \%$ of filters present 752 in the dataset ( 66 out of 595$)$. 
bioRxiv preprint doi: https://doi.org/10.1101/2020.10.20.347237; this version posted November 24,2020 . The copyright holder for this preprint (which was not certified by peer review) is the author/funder, who has granted bioRxiv a license to display the preprint in perpetuity. It is made available under aCC-BY-NC-ND 4.0 International license.

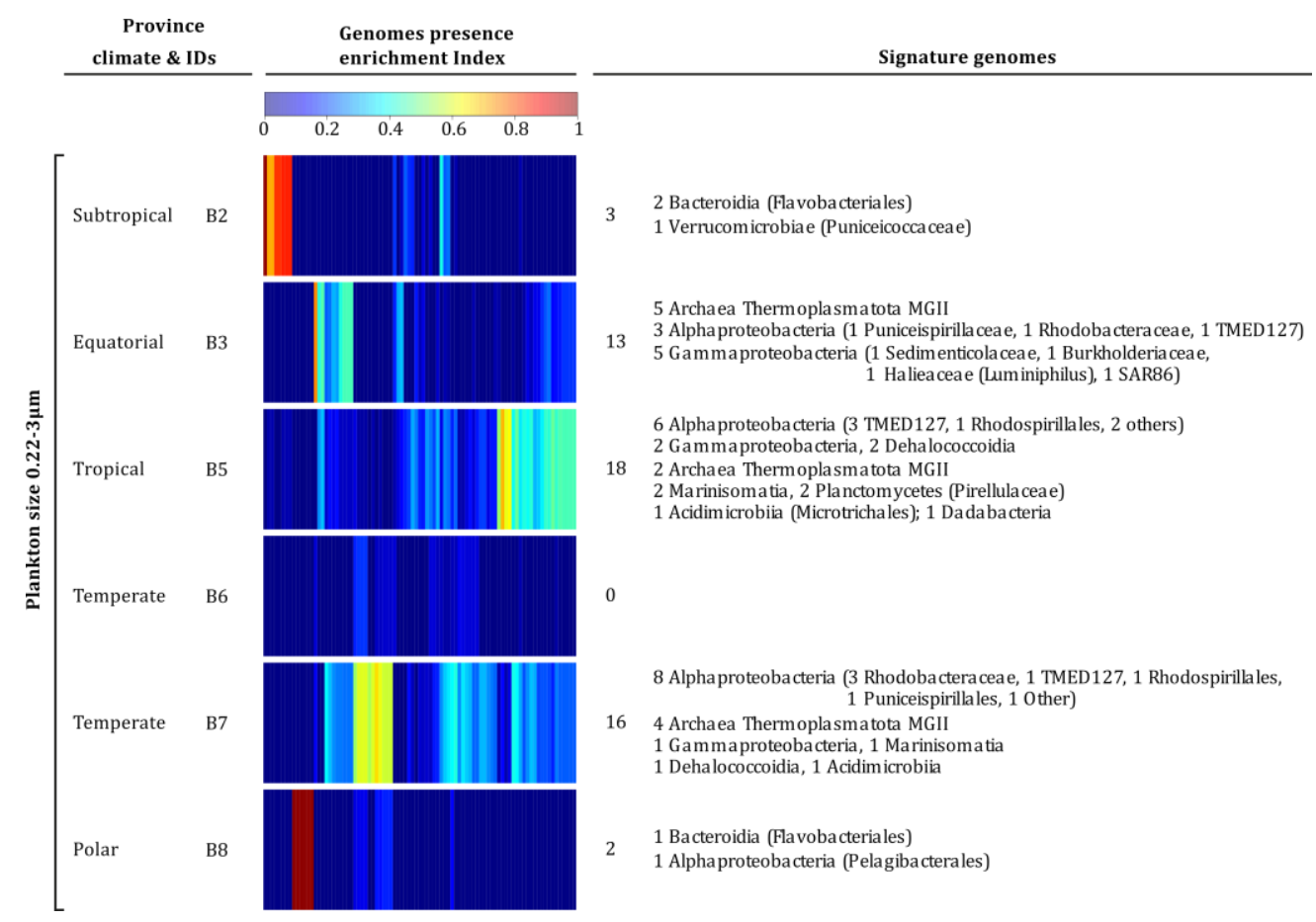

\section{Supplementary Figure 3 | Signature genomes of provinces of the prokaryotes enriched size.}

755 Indexes of presence enrichment ${ }^{14}$ for 523 genomes of prokaryotic plankton ${ }^{15}$ in corresponding

756 provinces are clustered and represented in a color scale. Signature genomes (see Methods) are

757 found for almost all provinces, their number and taxonomies are summarized (detailed list in

758 Supplementary Table 6). 
a

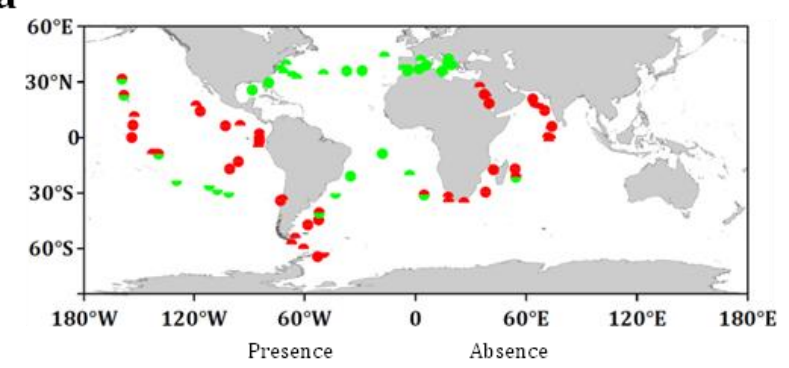

c

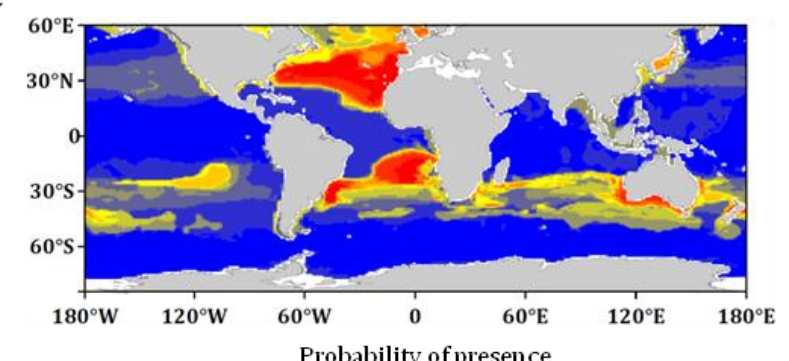

Probability of presence

10 b

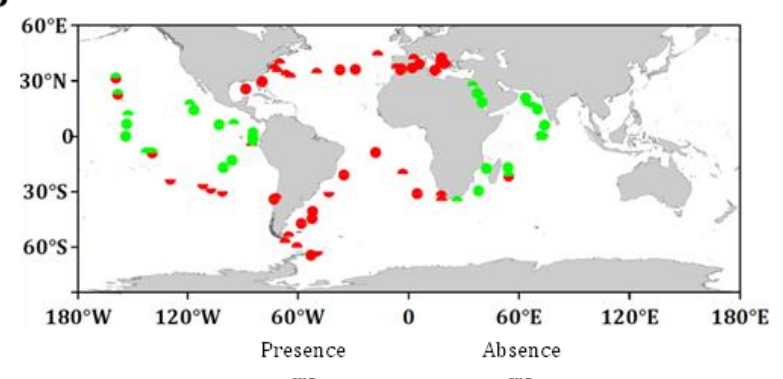

d
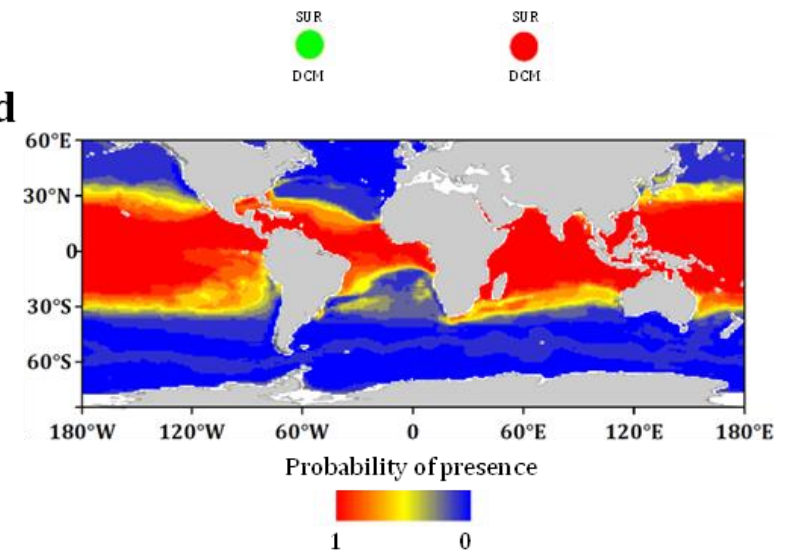
example provinces from size fraction 180-2000 $\mu \mathrm{m}$. (a) Sampling map of province F5. (b) Province F8. (c) Projection map of province F5 on WOA13¹. (d) Province F8. Qualitatively, projection maps are coherent with sampling maps of the two provinces with the highest probability of presence projected in the sampling regions. Other presence zones are also predicted by the projection. Sampling of these zones might be interesting to confirm our approach and projections such as South of Australia where a high probability of presence for province F5 is predicted. 


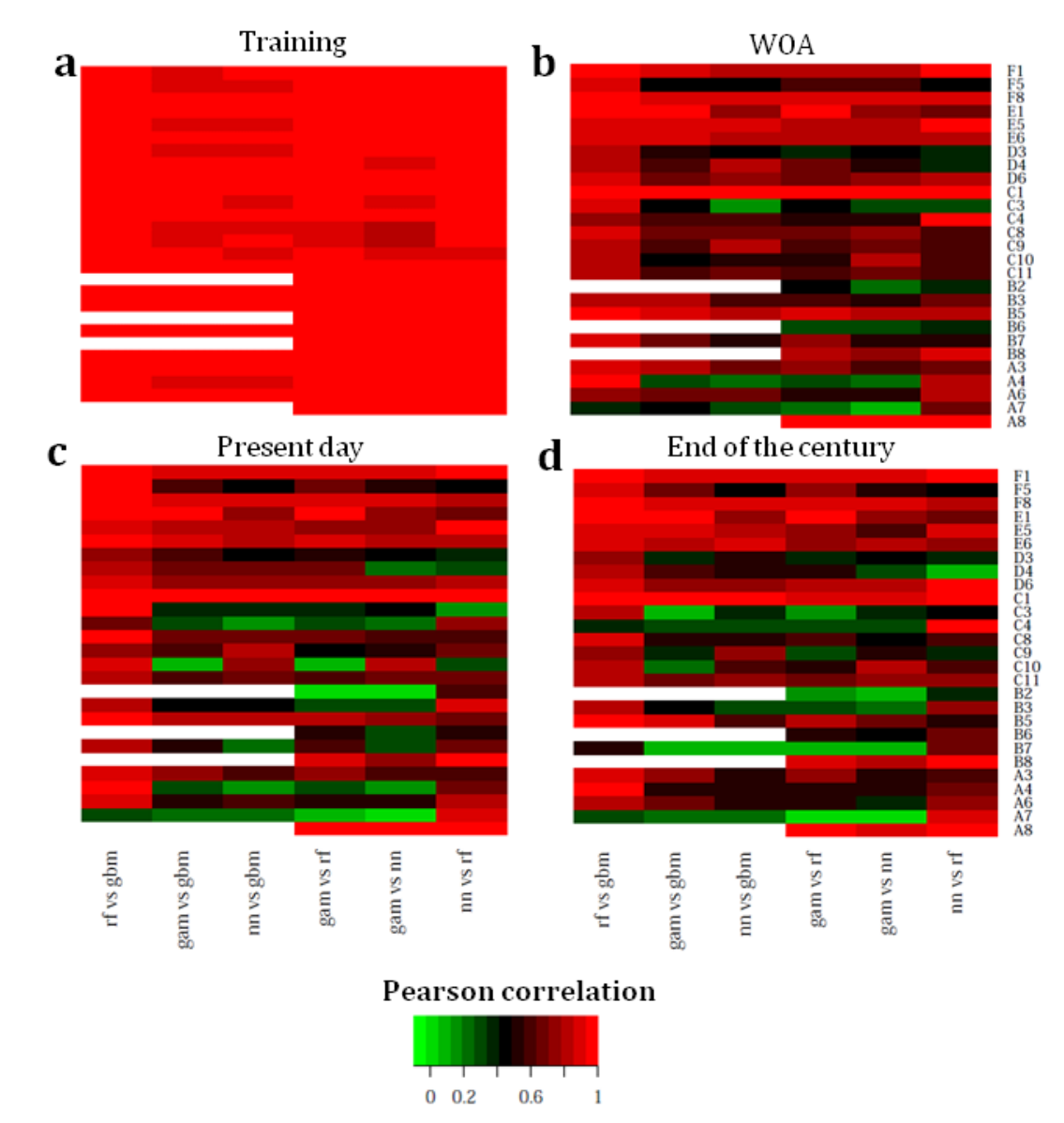
of the 4 machine learning models. rf: Random Forest, gbm: gradient boosting machines, gam: general additive models, nn: neural networks. In rows are the provinces of the different size fractions. In columns are the pairwise comparisons of each machine learning technique.

772 Training set outputs. (b) WOA13 average data (except for Iron, PISCES-v216 is used) projection outputs. (c) Present day data projection outputs (bias corrected mean model of 6 Earth System

774 Models). (d) End of the century projection outputs. On the training set, models are in agreement 775 with most of the correlation coefficients superior to 0.9. A drop of correlation is observed for 776 modeled data (c, d) especially in small size fractions. This shows modeled data are more distant 777 from the training set than WOA data. Random Forest and Gradient Boosting Machine are in very 778 good agreement (first columns) which could be expected as they are both based on multiple 779 decision trees. 


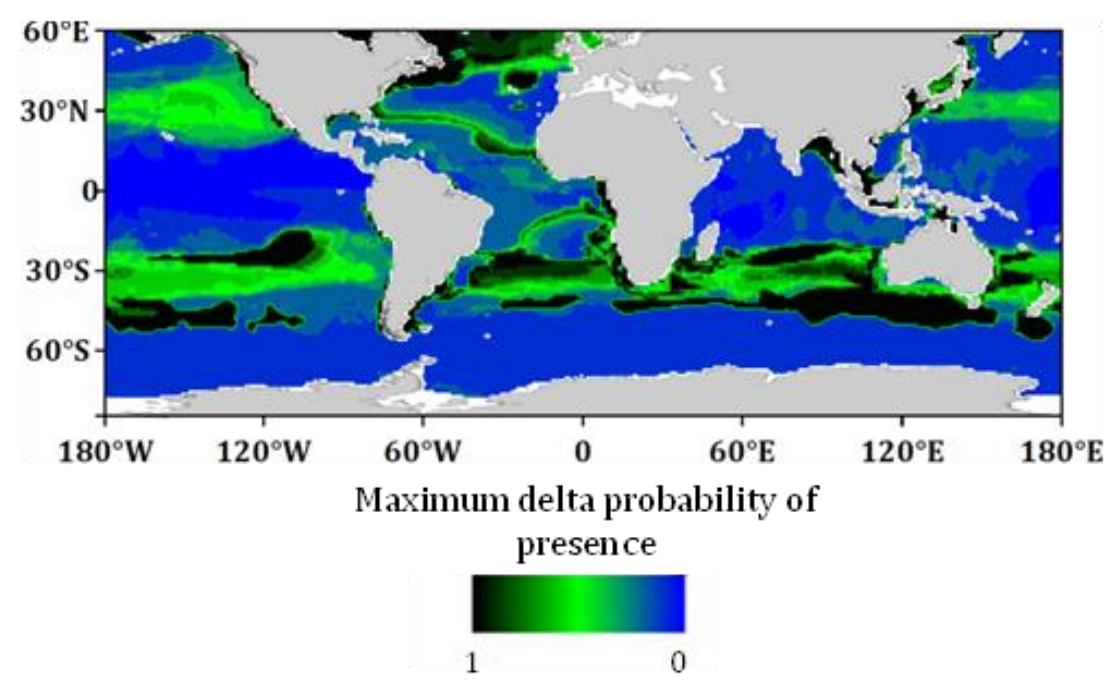

781 Supplementary Fig. 6 | Probability range map (WOA data) of province F5 of size fraction 180-

$782 \quad 2000 \mu \mathrm{m}$. At each point of the grid, the maximum delta probability of presence between the 4 783 machine learning projections is calculated. In black are the zones where two models completely 784 disagree: one model predicts presence with certainty whereas the other predicts absence with 785 certainty. Disagreement appears mostly in uncertain presence areas (Supplementary Fig. 3c) 786 whereas models are generally in good agreement in absence areas (blue zones). 
bioRxiv preprint doi: https://doi.org/10.1101/2020 10.20.347237; this version posted November 24, 2020. The copyright holder for this preprint

(which was not certified by peer review) is the author/funder, who has granted bioRxiv a license to display the preprint in perpetuity. It is made available under aCC-BY-NC-ND 4.0 International license.

a

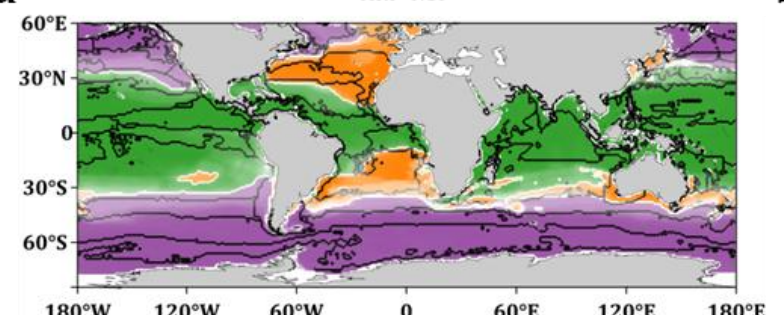

b

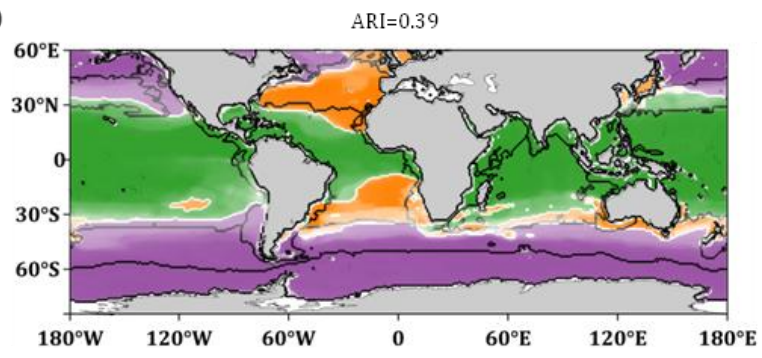

C

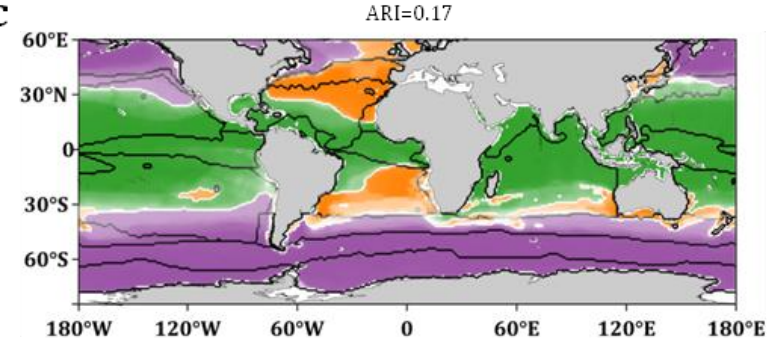

Province

F1 F5 F8

d

ARI $=0.13$

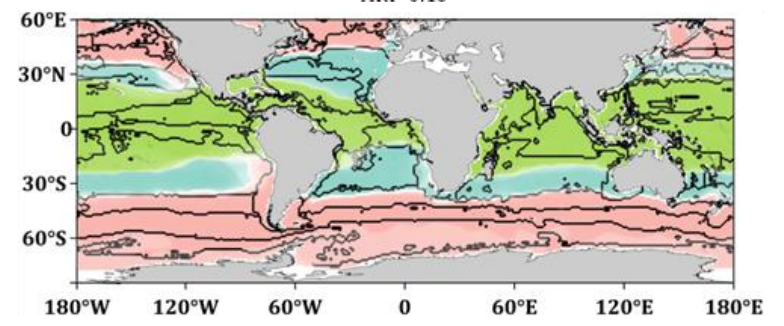

e

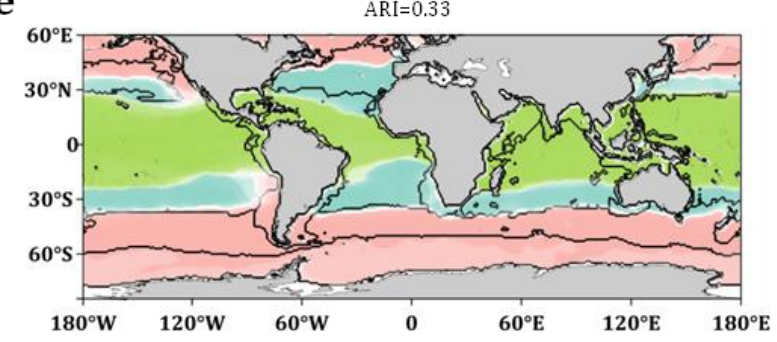

f

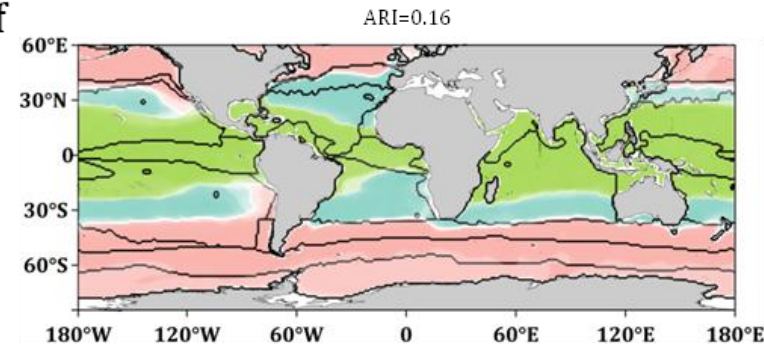

Province

F1 F5 F6

g

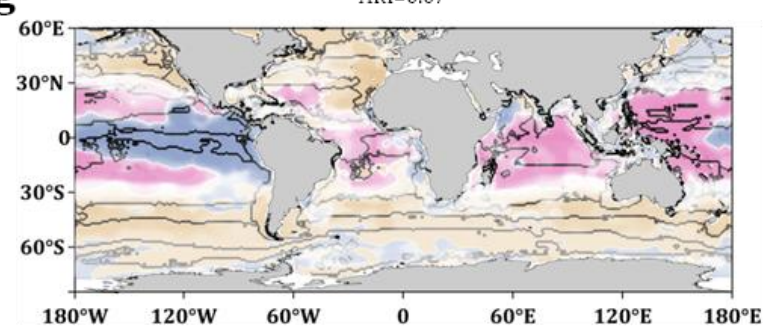

h

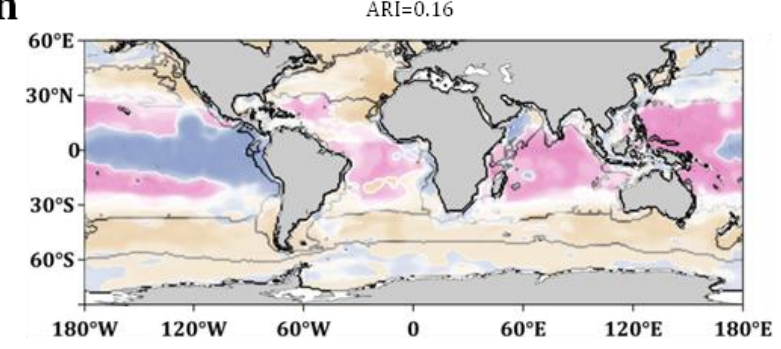

i

ARI $=0.09$

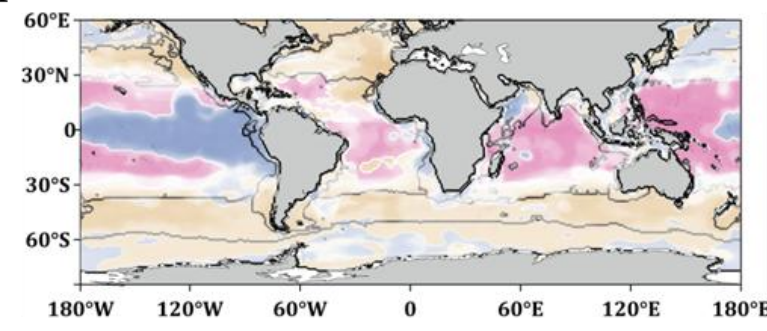

Province 
bioRxiv preprint doi: $\mathrm{https}$ //doi.org/10.1101/2020 10.20.347237; this version posted November 24,2020 . The copyright holder for this preprint

(which was not certified by peer review) is the author/funder, who has granted bioRxiv a license to display the preprint in perpetuity. It is made available under aCC-BY-NC-ND 4.0 International license.
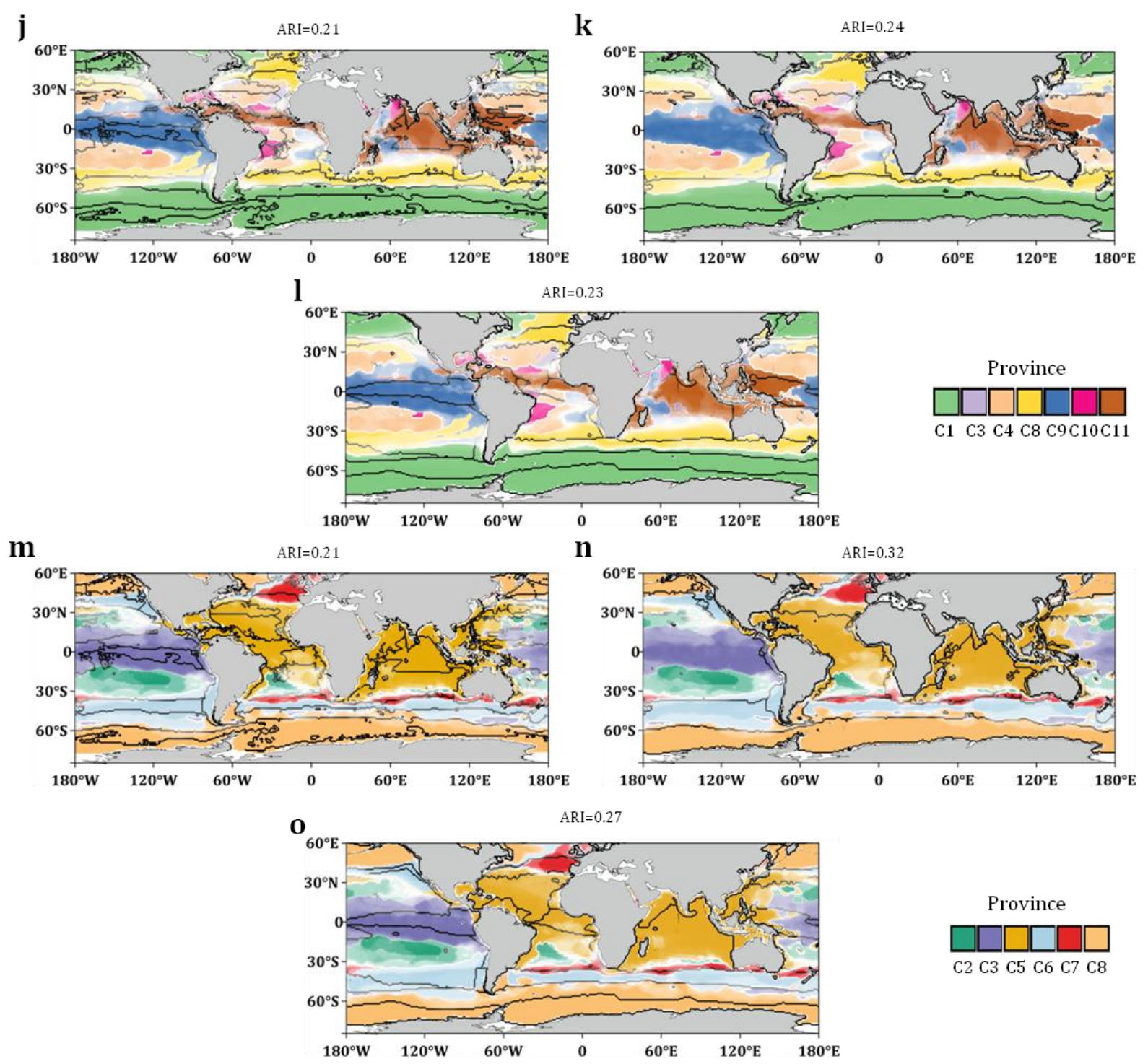

Province

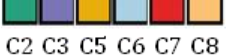

p

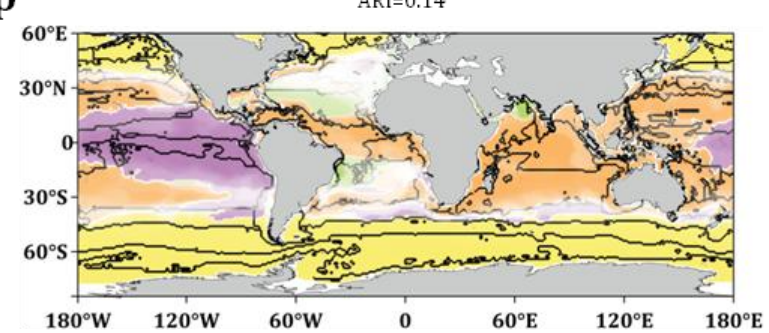

$\mathbf{q}$

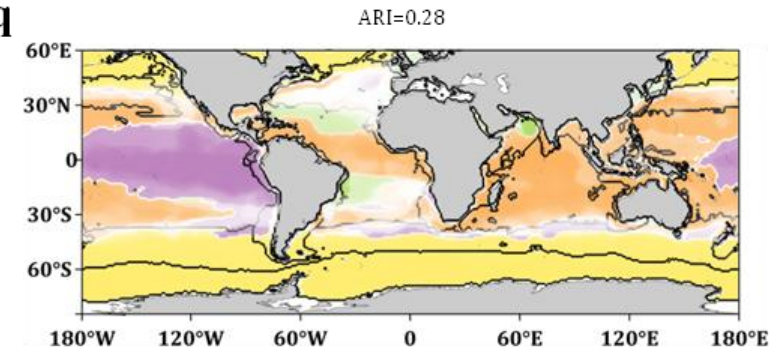

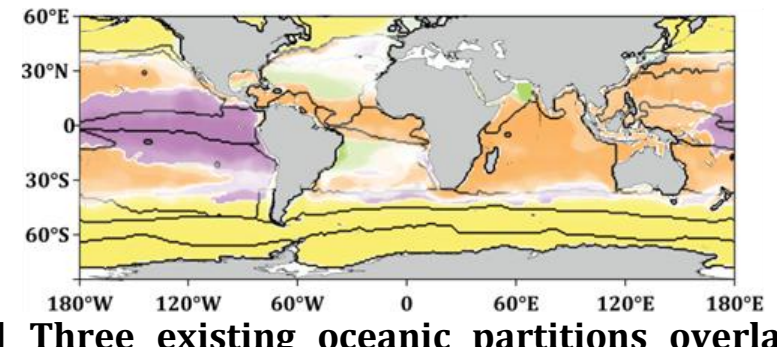

Province

A3 A4 A6 A7 A8 
790 provinces for the six fractions and combined size fractions. The three oceanic partitions are

791 Reygondeau et al. Biogeochemical Provinces (BGCP) ${ }^{17}$; Reygondeau et al. Biomes ${ }^{17}$; Fay and 792 McKingley Biomes ${ }^{18}$. Each partitioning mask is overlaid in the above order on top of plankton 793 provinces for the six size fractions. (a-c) 180-2000 $\mu \mathrm{m}$ (d-f) 20-180 $\mu \mathrm{m}$ (g-i) 5-20 $\mu \mathrm{m}(\mathbf{j}-\mathbf{l})$ 0.8-5 $794 \mu \mathrm{m}(\mathbf{m}-\mathbf{o})$ 0.22-3 $\mu \mathrm{m}$ and (p-r) 0-0.2 $\mu \mathrm{m}$. Above all maps, the adjusted rand index (ARI), an index 795 used to compare partitions, comparing mapped biogeographies with the black lines mask is shown. 

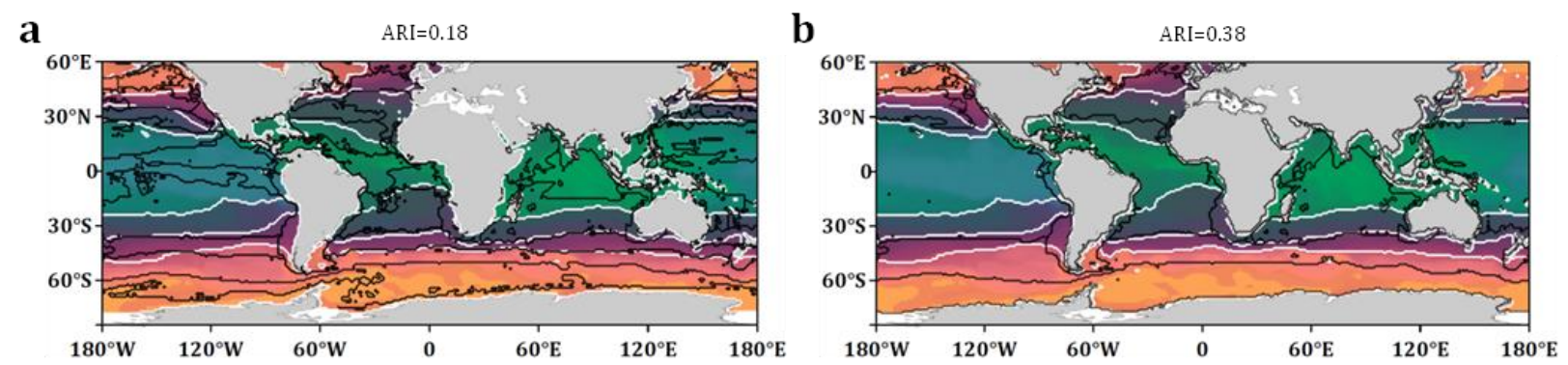

\section{c}
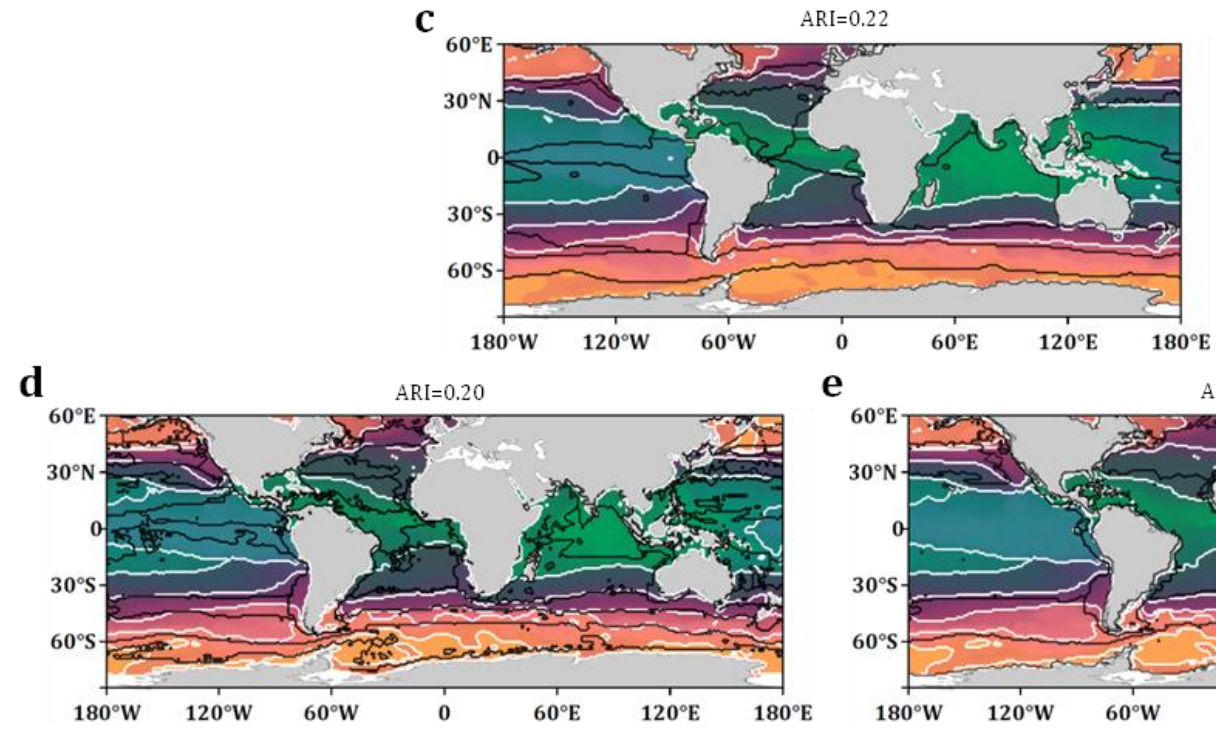

$\mathbf{e}$
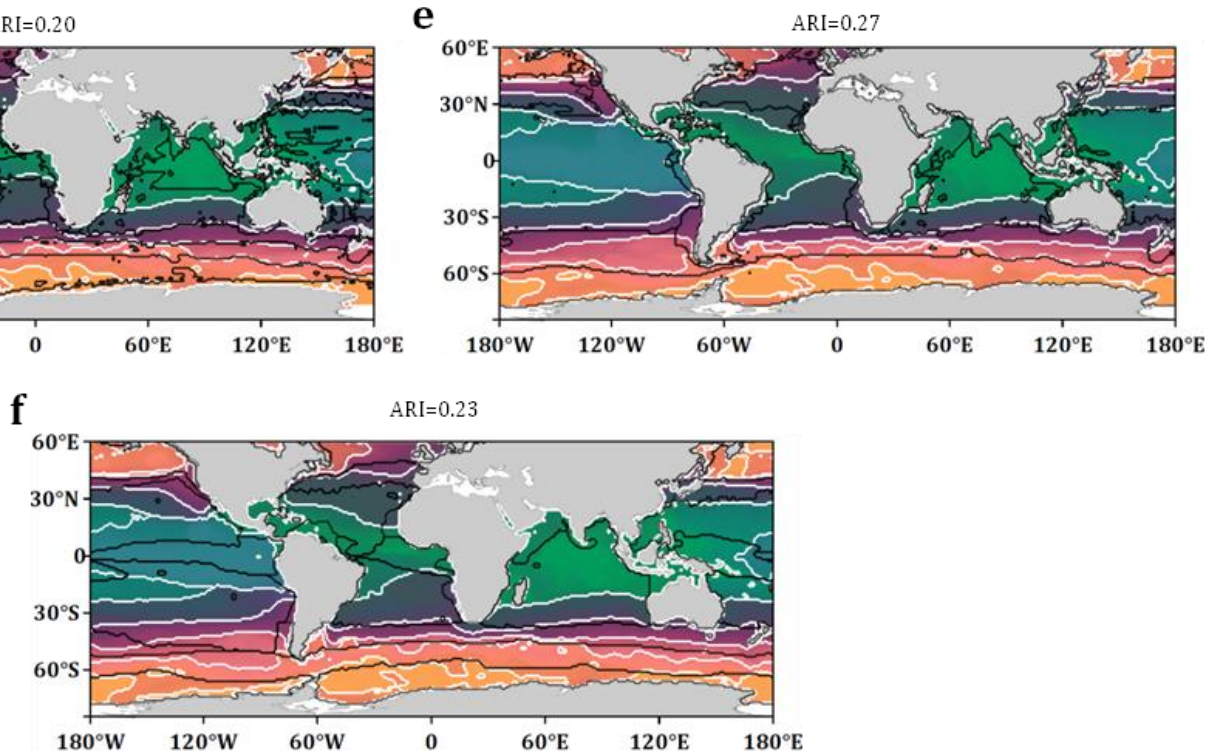

797 Supplementary Fig. 8 | Three existing oceanic partitions overlaid on top of plankton

798 provinces for the combined size fractions. The three oceanic partitions are Reygondeau et al. ${ }^{17}$

799 Biogeochemical Provinces (BGCP); Reygondeau et al. Biomes ${ }^{17}$; Fay and McKingley Biomes ${ }^{18}$. Each

800 partitioning mask is overlaid in the above order on top of size fraction plankton provinces combined by the PHATE algorithm in (a-c) 4 clusters and (d-f) 7 clusters. 


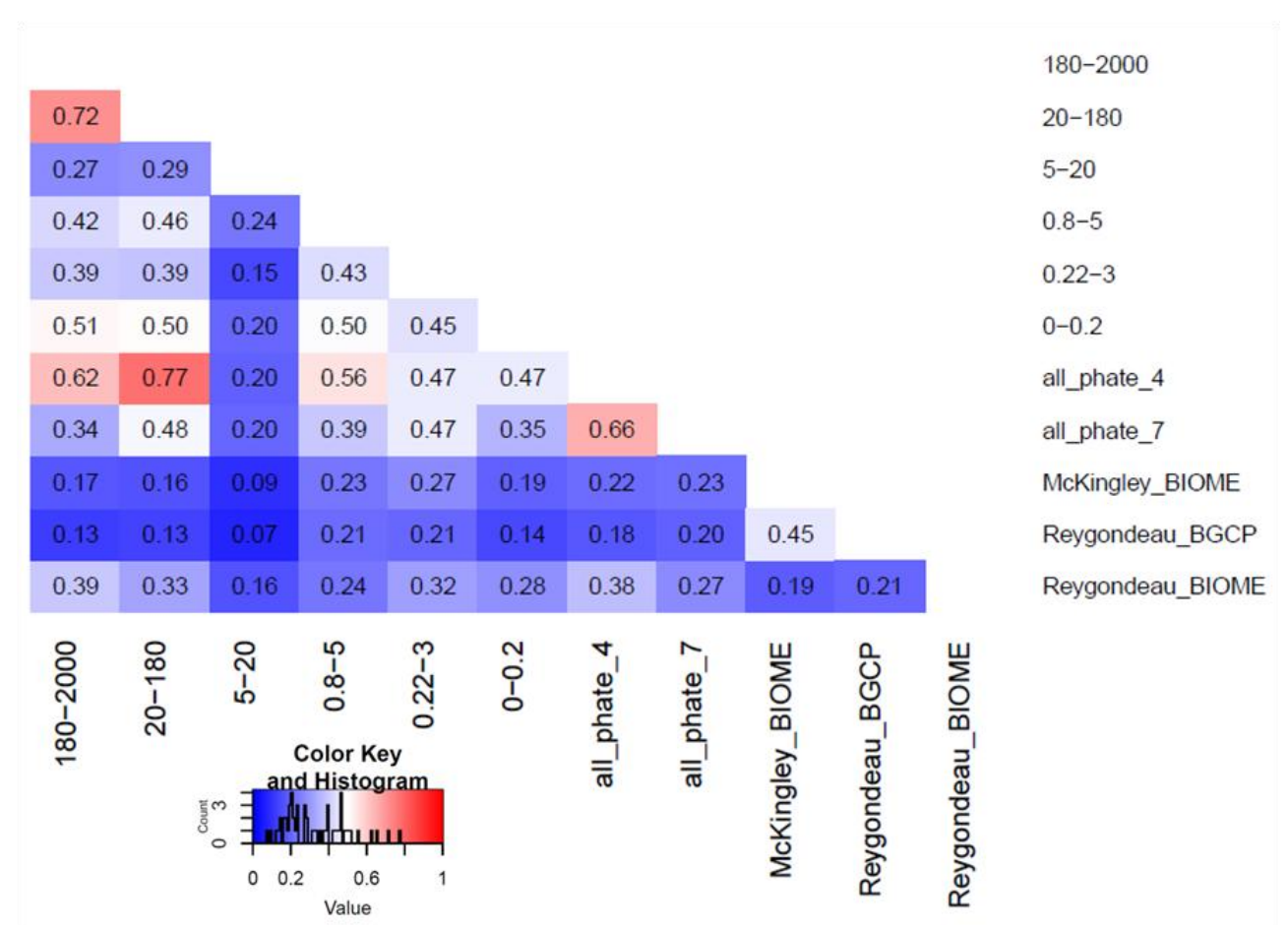

802 Supplementary Fig. 9 | Pairwise comparisons of ocean partitions based on plankton

803 provinces and existing biogeochemical partitions. The three oceanic partitions are Reygondeau

804 et al. ${ }^{17}$ Biogeochemical Provinces (BGCP); Reygondeau et al. Biomes ${ }^{17}$; Fay and McKingley Biomes ${ }^{18}$. 


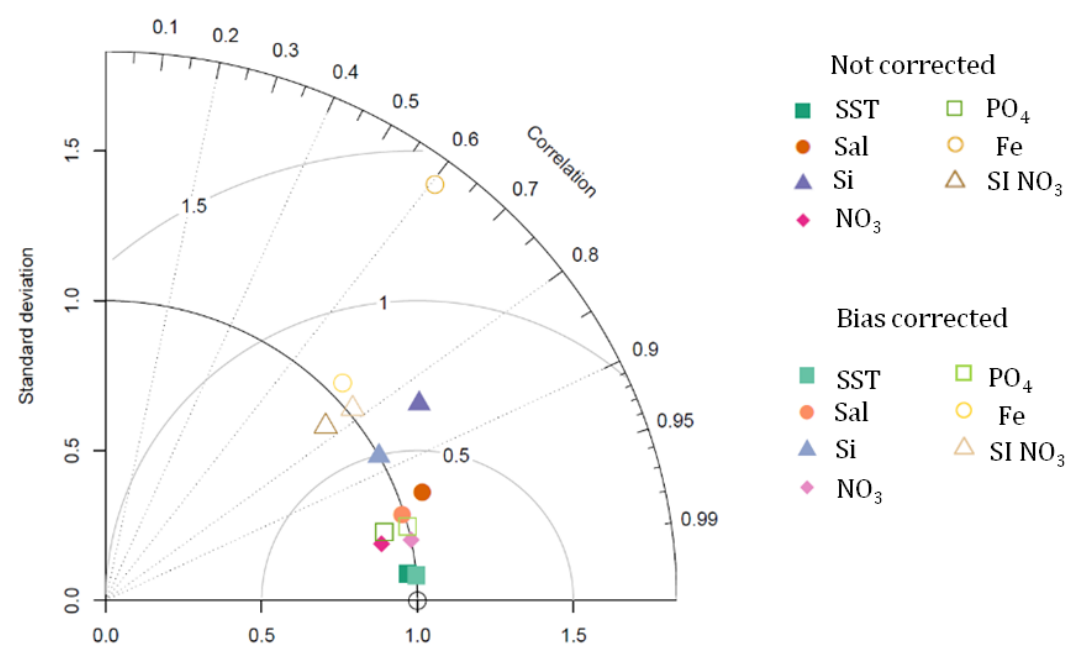
observations and present day ESM model mean of the different drivers. Each variable is centered and scaled according to the mean and standard deviation of the observed variable (black circle point at standard deviation 1 on the x-axis). Dark color points are the ESM model mean without Cumulative Distribution Function transform $\left(\mathrm{CDFt}^{19}\right)$ bias correction. They are to be compared with light color points for which the bias correction is performed. Overall, good spatial

812 correlations are found between the model mean and the observations. CDFt bias correction

813 performs well by bringing standard deviations of the model to the observed standard deviations 814 without decreasing correlations. 
a

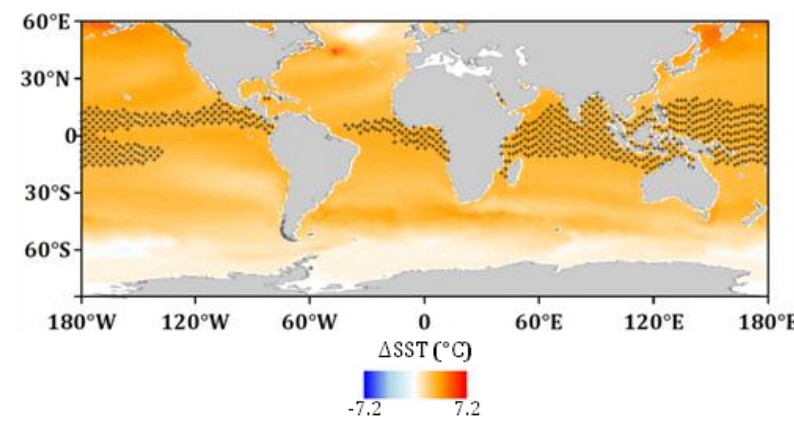

c

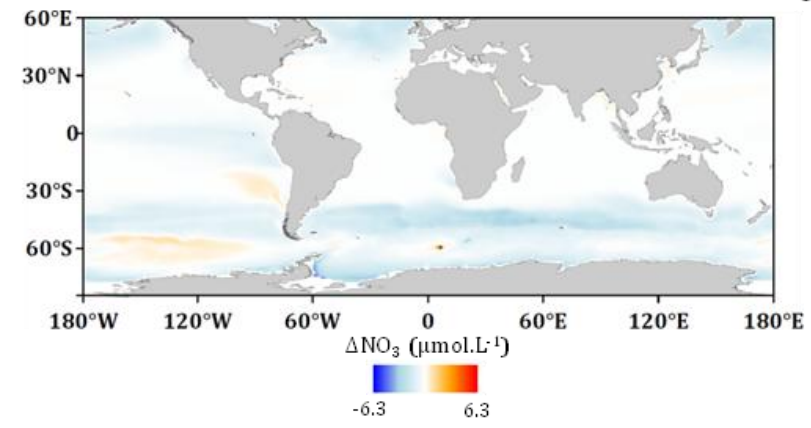

e

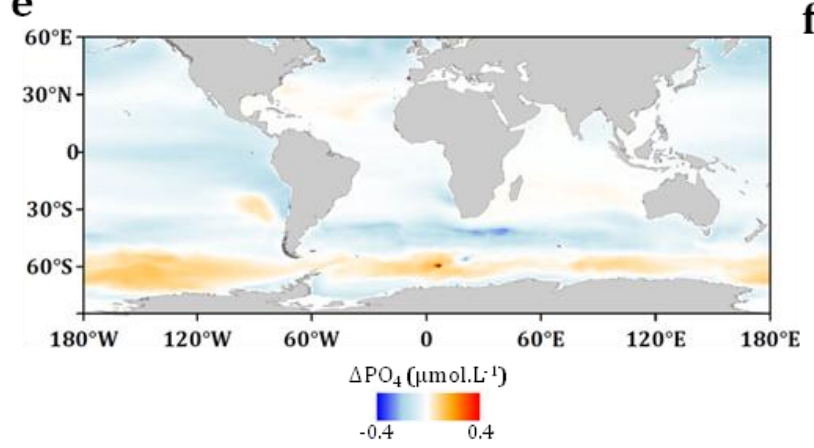

g

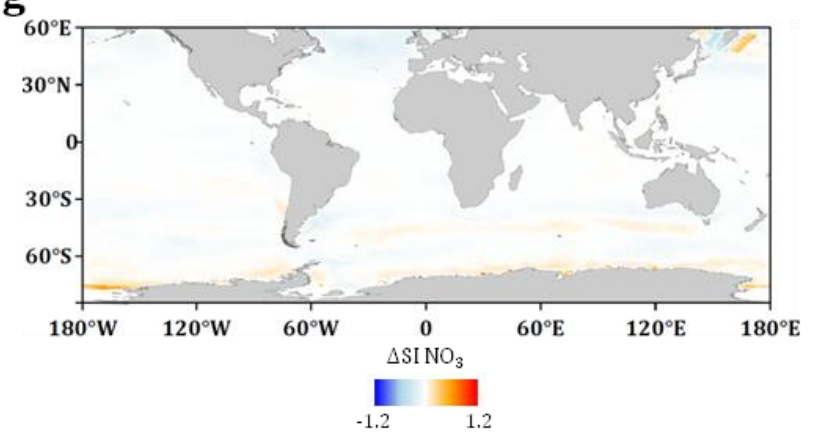

b

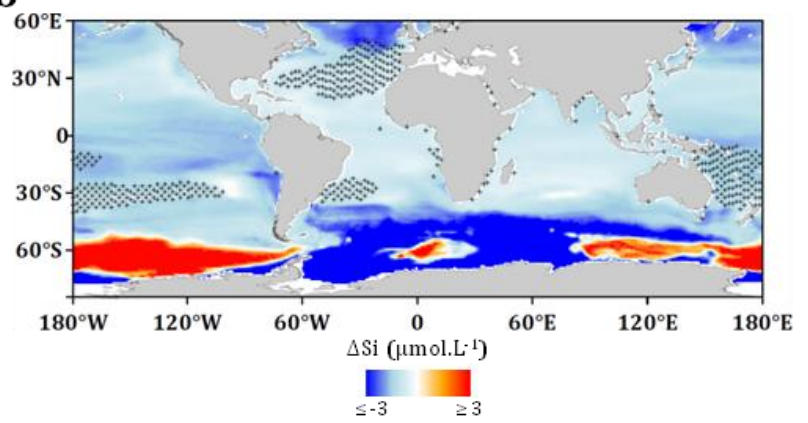

d
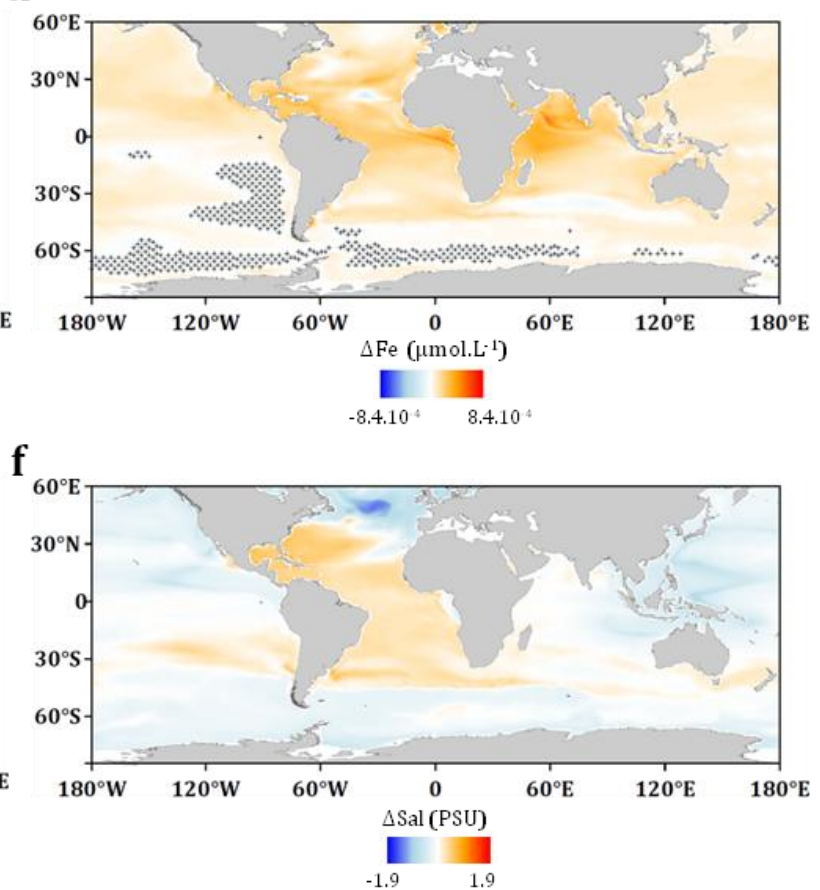

Supplementary Fig. 11 | Differences in drivers' intensity (2090/99-2006/15) in the bias corrected ESM model-mean under RCP8.5. (a) Sea Surface Temperature (SST). (b) Dissolved

818 silica. (c) Nitrate. (d) Iron. (e) Phosphate. (f) Salinity (Sal). (g) Seasonality Index of Nitrate (SI $\left.\mathrm{NO}_{3}\right)$.

819 Note that the scale for dissolved silica variations is restricted to visualize small variations. Regions 820 for which out of range values (i.e. inferior to the minimum or superior to the maximum found in 
bioRxiv preprint doi: https://doi.org/10.1101/2020.10.20.347237; this version posted November 24,2020 . The copyright holder for this preprint (which was not certified by peer review) is the author/funder, who has granted bioRxiv a license to display the preprint in perpetuity. It is made available under aCC-BY-NC-ND 4.0 International license.

821 2006-15) are reached at the end of the century are highlighted with small stars reflecting high 822 uncertainty zones for machine learning approaches.

823 


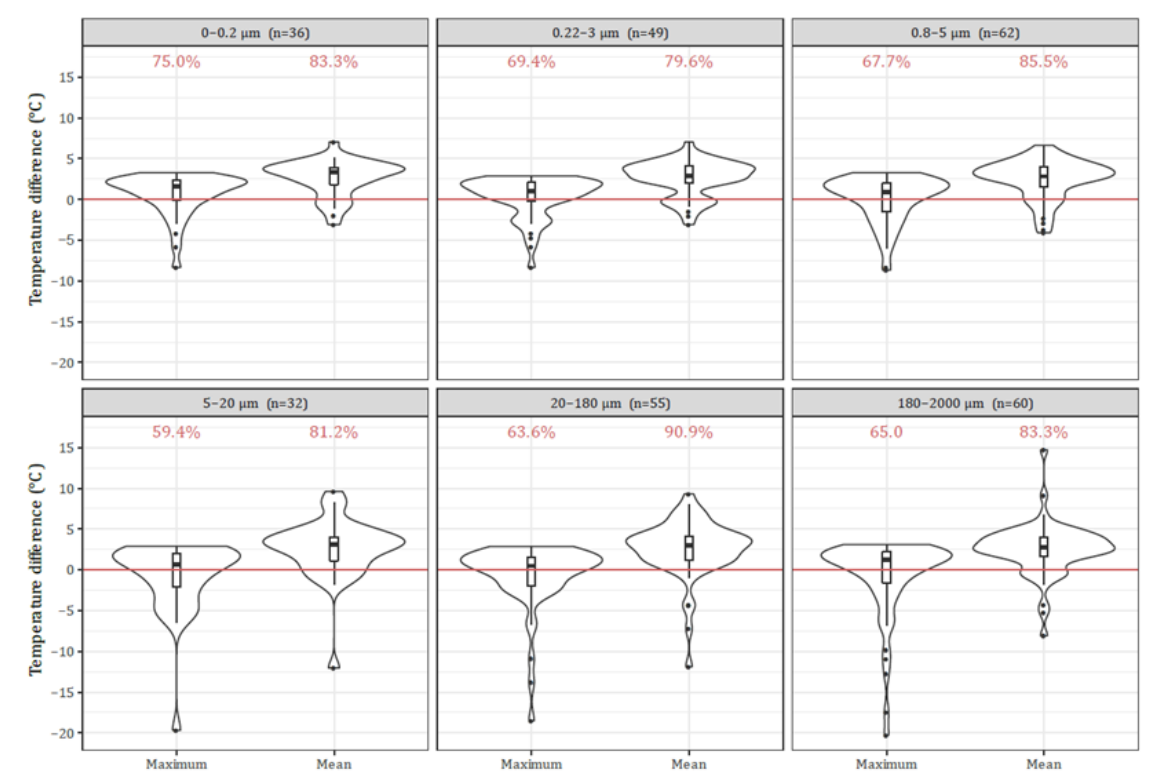

824 Supplementary Fig. 12 | Distribution of deltas between future temperature at each sampling 825 site minus either the mean or maximum temperature within their contemporary genomic

826 province. For most of the sites and across size fractions the future temperature projected by the

827 bias adjusted ESM ensemble model is higher than both the maximum and mean contemporary temperature of their genomic province. 
a

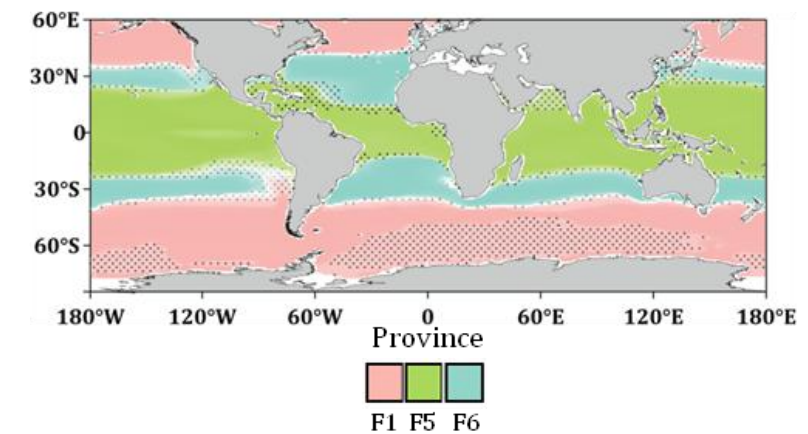

C

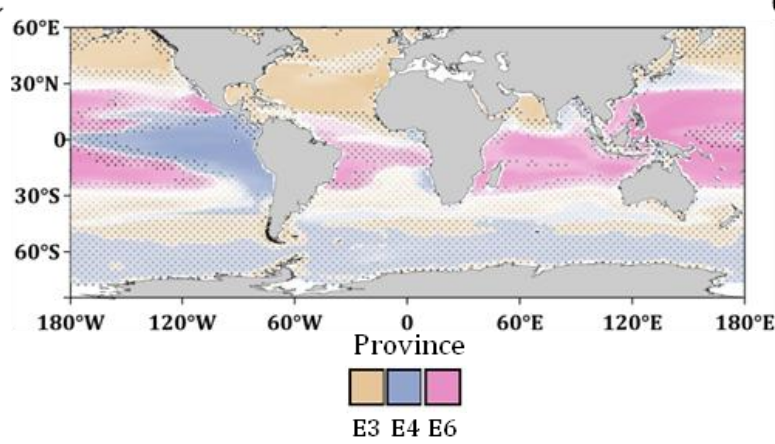

e
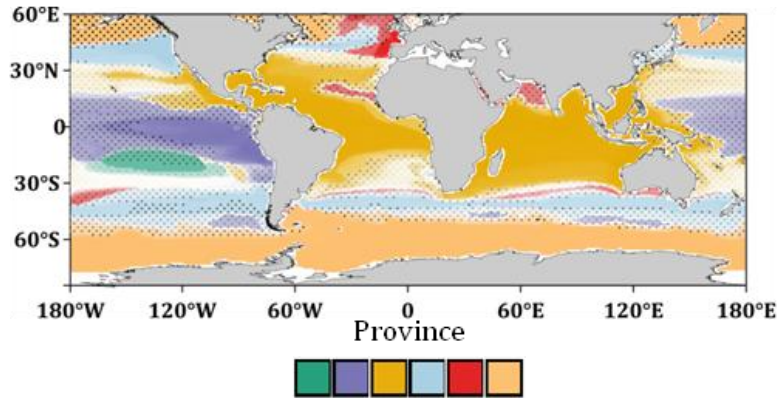

C2 C3 C5 C6 C7 C8

g

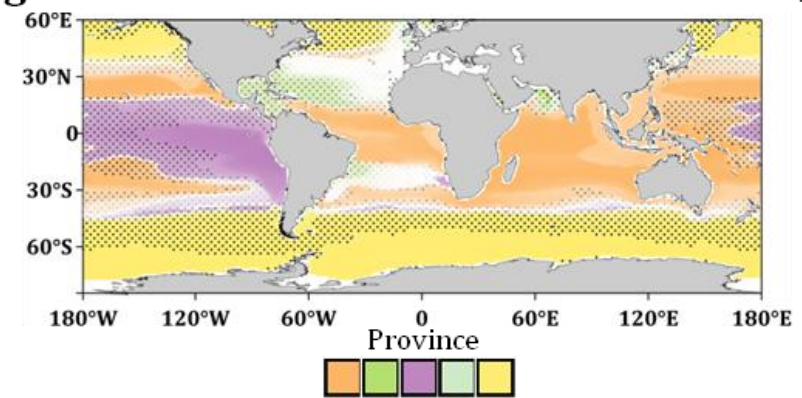

A3 A4 A6 A7 A8

f b

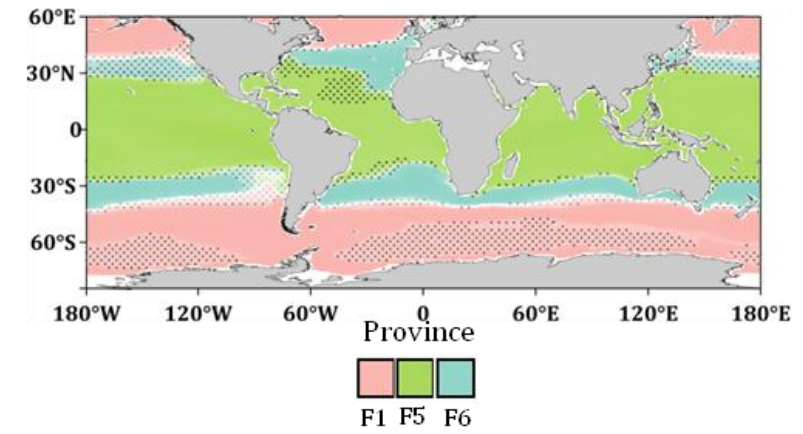

d
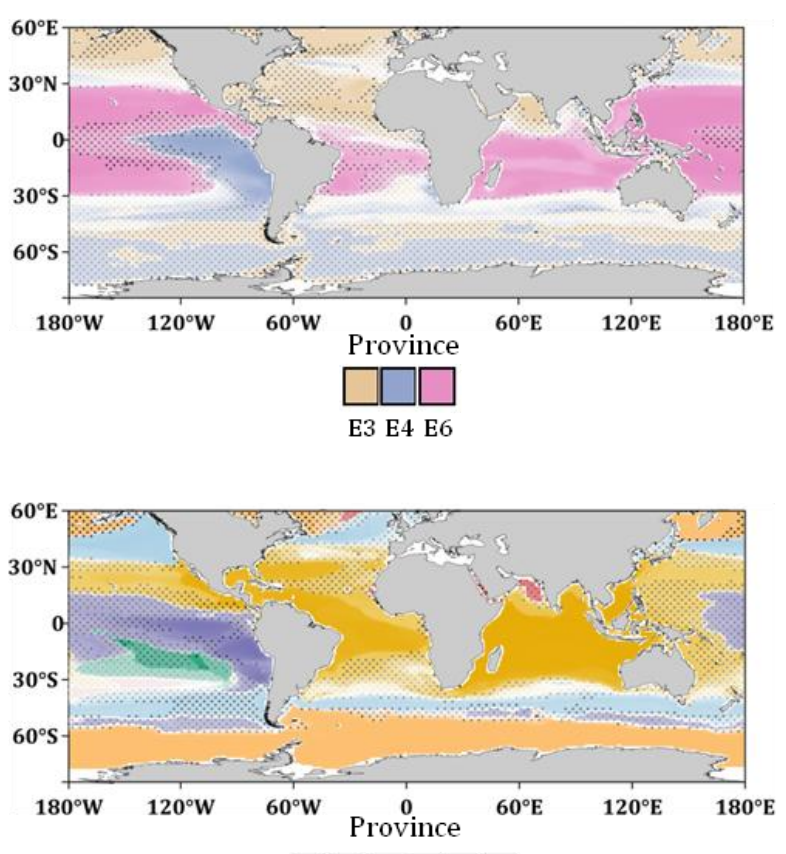

C2 C3 C5 C6 C7 C8

h

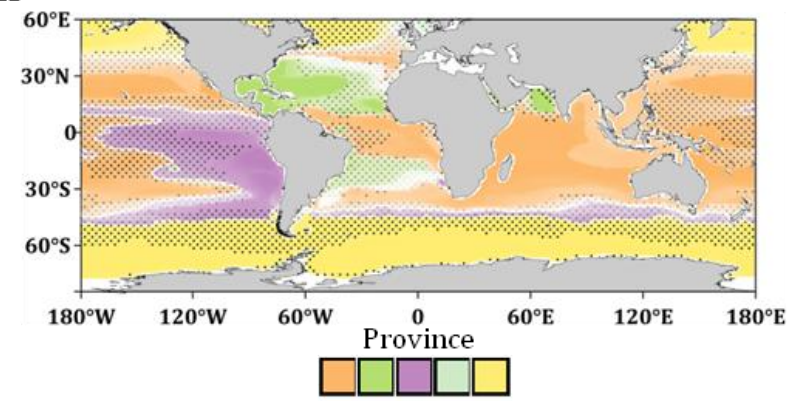

A3 A4 A6 A7 A8

Supplementary Fig. 13 | Global geographical patterns for 20-180, 5-20, 0.22-3, 0-0.2 $\mu \mathrm{m}$

831 plankton size fractions in present day (a, c, e , g) and at the end of the century (b, d, f, h). The

832 dominant province i.e. the one predicted to have the highest probability of presence is represented at each grid point of the map. The color transparency is the probability of presence of the dominant 
bioRxiv preprint doi: https://doi.org/10.1101/2020.10.20.347237; this version posted November 24,2020 . The copyright holder for this preprint (which was not certified by peer review) is the author/funder, who has granted bioRxiv a license to display the preprint in perpetuity. It is made available under aCC-BY-NC-ND 4.0 International license.

834 province. Expansion of tropical provinces and shrinkage of temperate communities is consistently 835 projected in all size fractions.

836 


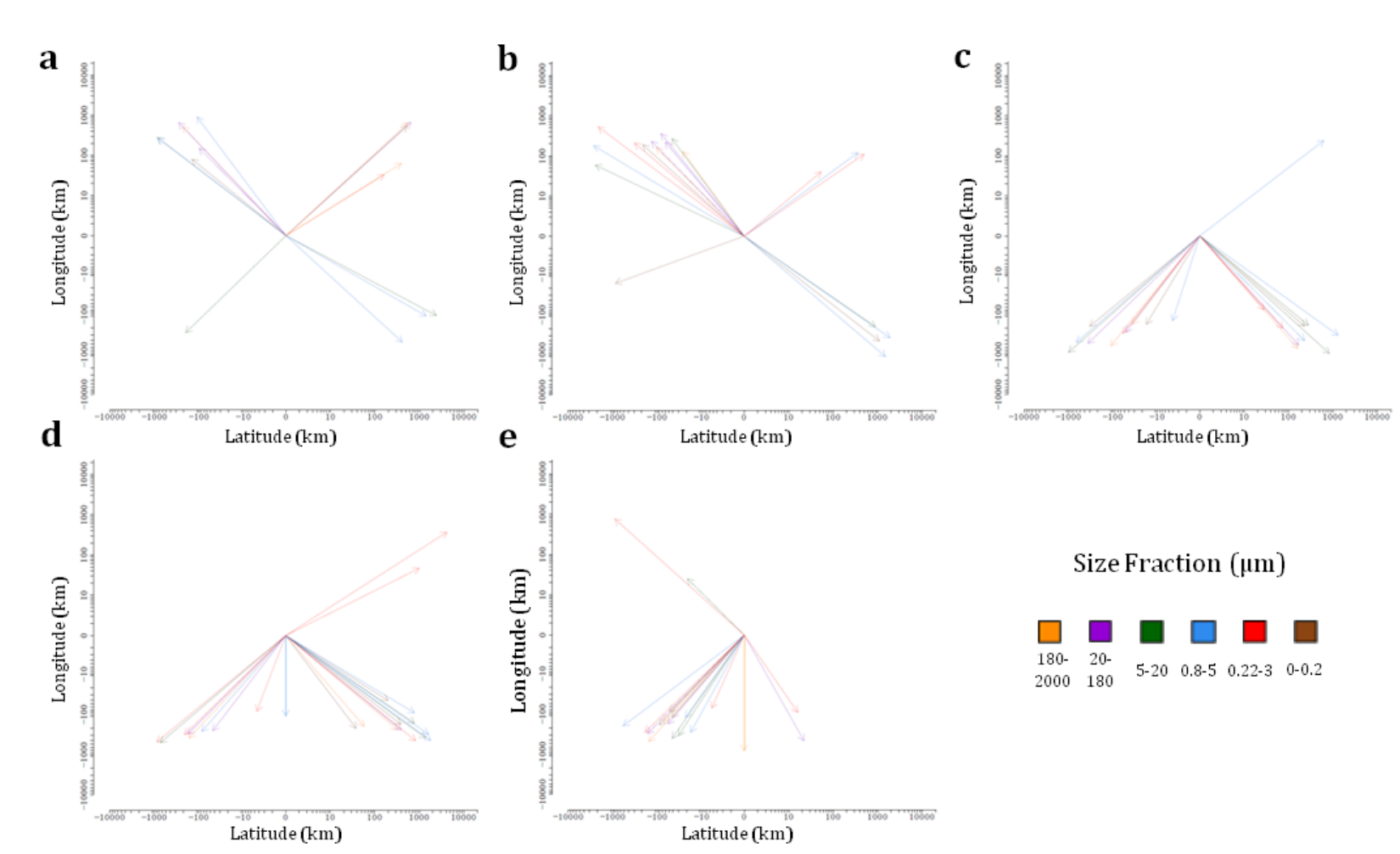

837 Supplementary Fig. 14 | Projected migration shifts of the 27 provinces between present day

838 and end of the century. Predicted migration shifts are presented in 5 major ocean basins: (a) 839 North Atlantic (b) North Pacific (c) South Atlantic (d) South Pacific and (e) Indian Ocean. $96 \%$ of 840 migration shifts (larger than $200 \mathrm{~km})$ are oriented towards the pole. Mean shift is $641 \mathrm{~km}(76 \pm 79$ $\left.841 \mathrm{~km} \cdot \mathrm{dec}^{-1}\right)$ and median shift is $394 \mathrm{~km}\left(47 \mathrm{~km} \cdot \mathrm{dec}^{-1}\right)$. Few provinces are projected to shift more than 842 thousands of kilometers toward suitable environmental conditions with a maximum shift of 4325 $843 \mathrm{~km}$. 
a

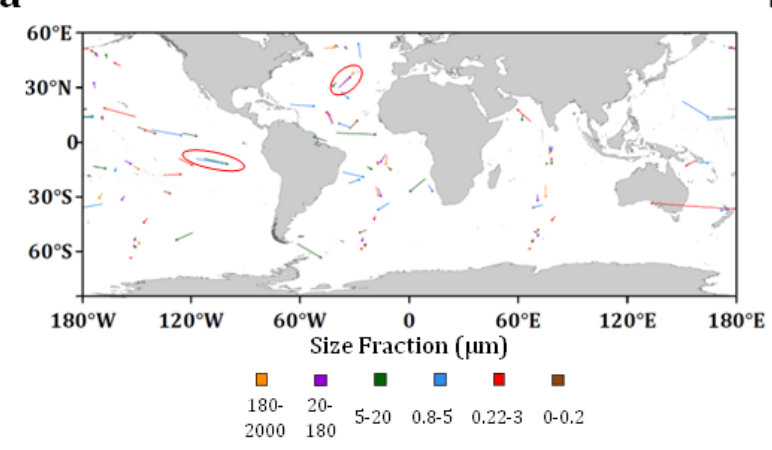

b

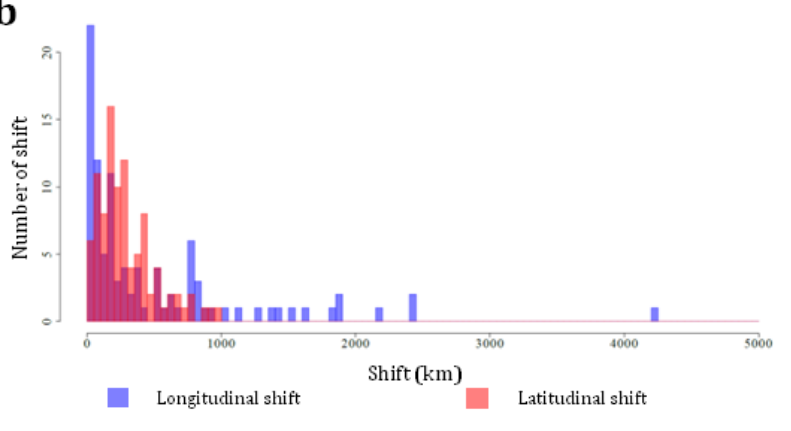

844 Supplementary Fig. 15 | (a) Projected migration shifts of provinces on the world map. (b)

845 Latitudinal shift distribution (red bars) and longitudinal shift distribution (blue bars). (a)

846 Migration shifts are represented as arrows pointing at the end of century centroid. Arrows are

847 colored according to the size fraction. Some shifts seem to correlate with each other (exemplified

848 with circled arrows). For instance, parallel shifts are projected in the southern pacific equatorial

849 communities of size fractions $0.8-5 \mu \mathrm{m}$ and 5-20 $\mu \mathrm{m}$ (blue and green circled arrows). All non-

850 poleward arrows belong to small size classes $(<20 \mu \mathrm{m})$ showing differential responses to climate

851 change depending on the size class. (b) Some longitudinal shifts are more important than

852 latitudinal shifts with 14 longitudinal shifts superior to $1000 \mathrm{kms}$. Mean longitudinal shift (around

$853500 \mathrm{kms}$ ) is significantly higher (Student t-test p-value $<0.01$ ) than mean latitudinal shift (around

$854290 \mathrm{kms}$ ) while medians (longitudinal $190 \mathrm{kms}$ vs latitudinal $230 \mathrm{kms}$ ) are not significantly

855 different (Wilcoxon test). 
a

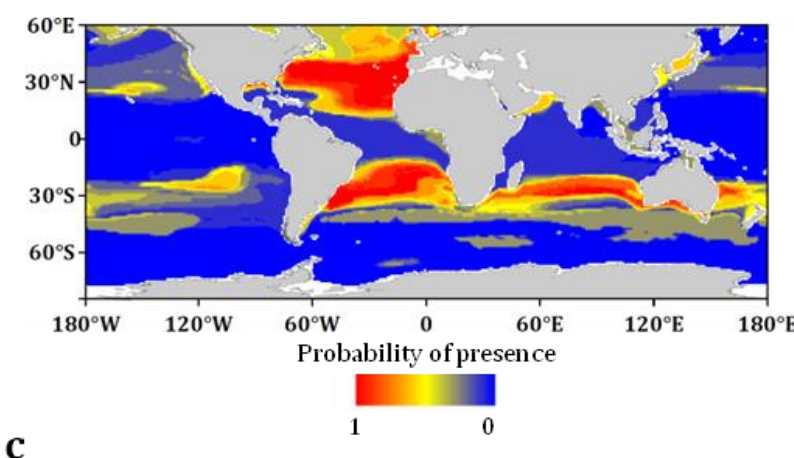

c

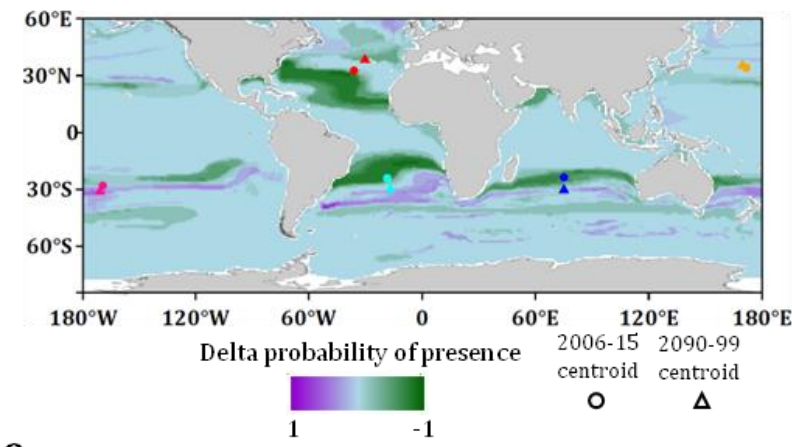

e

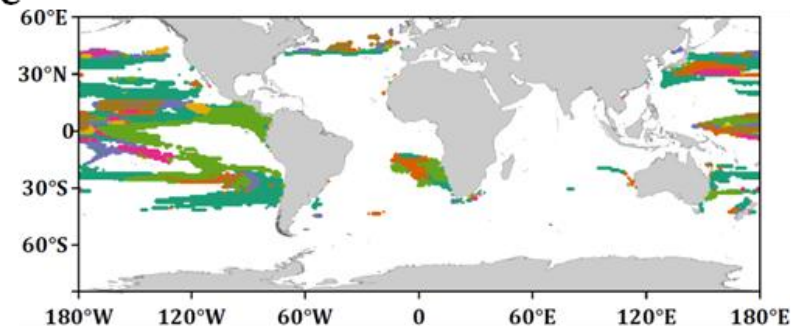

b

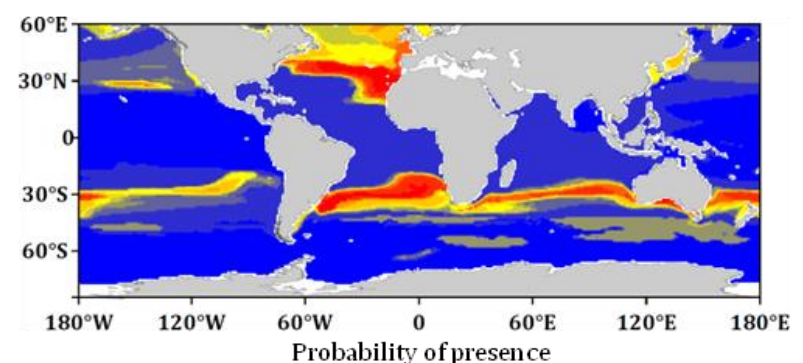

d

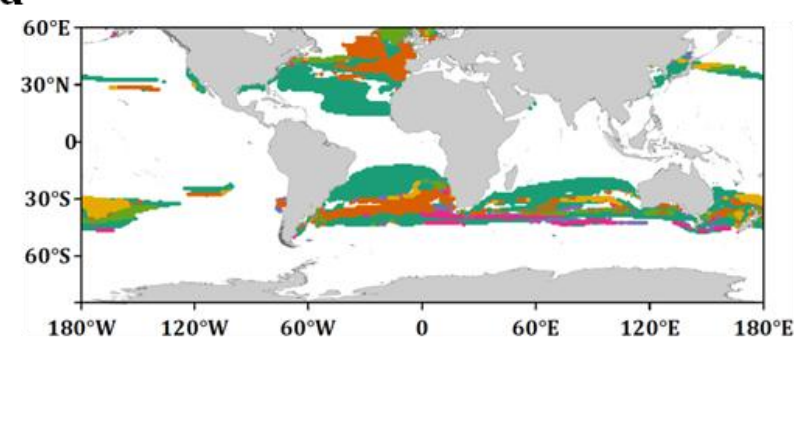

Supplementary Fig. 16 | Projection maps of province F5 of size fraction 180-2000 $\mu$ m in

Driver

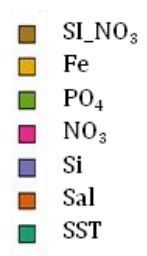
present day (a) and at the end of the century (b). At each grid point, the probability of presence of the province is computed as the average of the predicted probability of each of the four machine learning techniques (gbm, nn, rf and gam). Red color indicates a high probability of presence. (a)The projected province corresponds to the sampled province (North Atlantic and South Atlantic) but several other places have high probabilities of presence such as South Australia where no sampling is available. (b) At the end of the century, the province is projected to reduce significantly in size. (c) Delta probability of presence map (2006/15 - 2090/99) and core range shift in the 5 major oceanic basins of province F5 of size fraction 180-2000 $\mu \mathrm{m}$. In all the basins, the centroid of the province is projected to migrate poleward. (d) Main drivers associated with the projected changes. Changes are mainly driven by sea surface temperature (55\%) followed by salinity (14\%). (e) Main drivers associated with the shrinkage of the equatorial cluster C9 of size fraction 0.8-5. 
bioRxiv preprint doi: https://doi.org/10.1101/2020.10.20.347237; this version posted November 24,2020 . The copyright holder for this preprint (which was not certified by peer review) is the author/funder, who has granted bioRxiv a license to display the preprint in perpetuity. It is made available under aCC-BY-NC-ND 4.0 International license.

869 Considering only latitudes between the two tropics, changes are mainly driven by decreases in $\mathrm{PO}_{4}$

870 (24 \%) in addition to SST (27 \%) (overall $34 \%$ STT and $20 \% \mathrm{PO}_{4}$ ).

871 

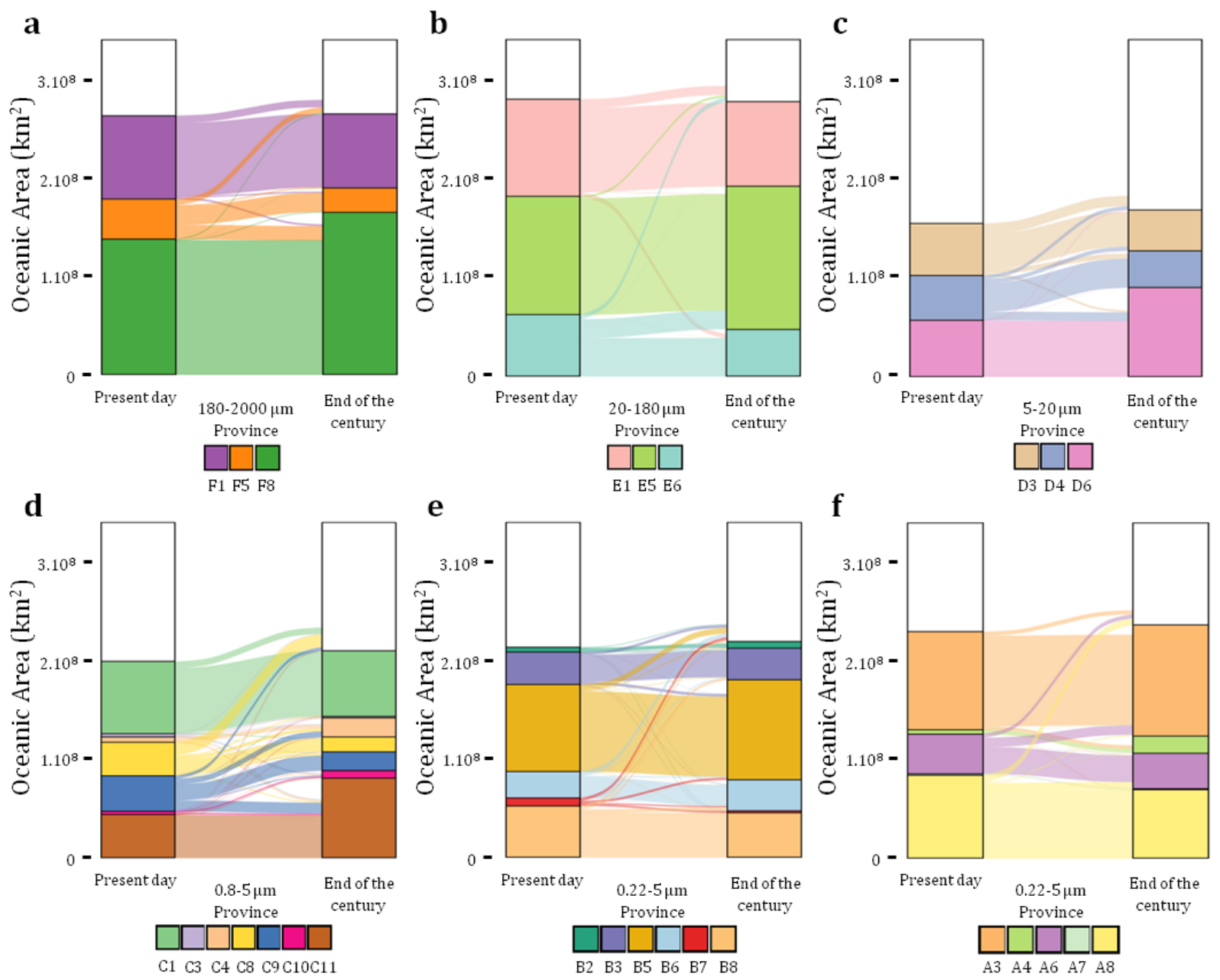

872 Supplementary Fig. 17 | Probabilistic covered areas of the provinces projected in present

873 day and at the end of the century. (a) 180-2000 $\mu \mathrm{m}$ (b) 20-180 $\mu \mathrm{m}$ (c) 5-20 $\mu \mathrm{m}$ (d) 5-20 $\mu \mathrm{m}$ (e)

$874 \quad 0.8-5 \mu \mathrm{m}$ (f) $0-0.2 \mu \mathrm{m}$. The covered area by a province is defined as the area in which this province

875 is dominant and weighted by its probability of presence at each point and grid cell area. Areas not

876 covered by the provinces are represented in white. 
a

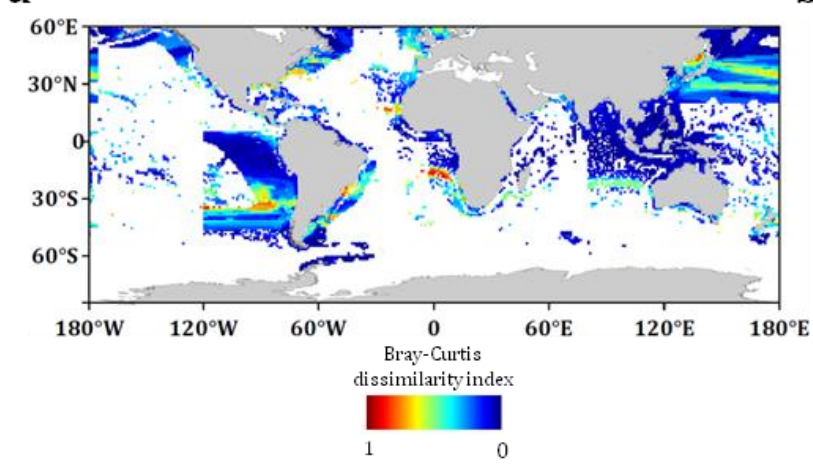

C

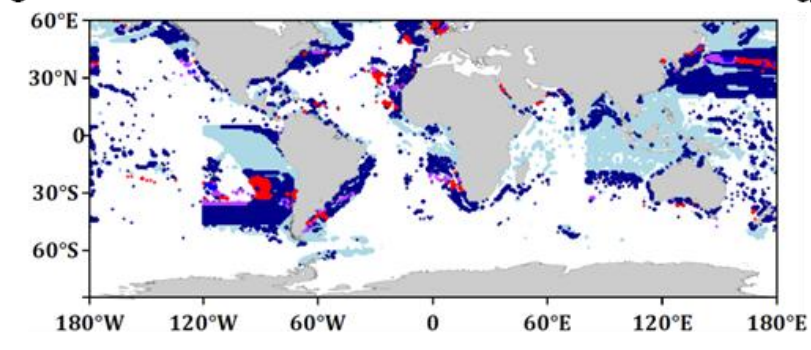

e

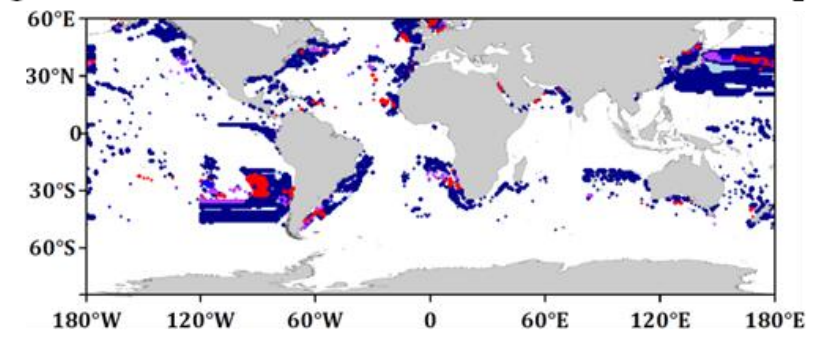

f b

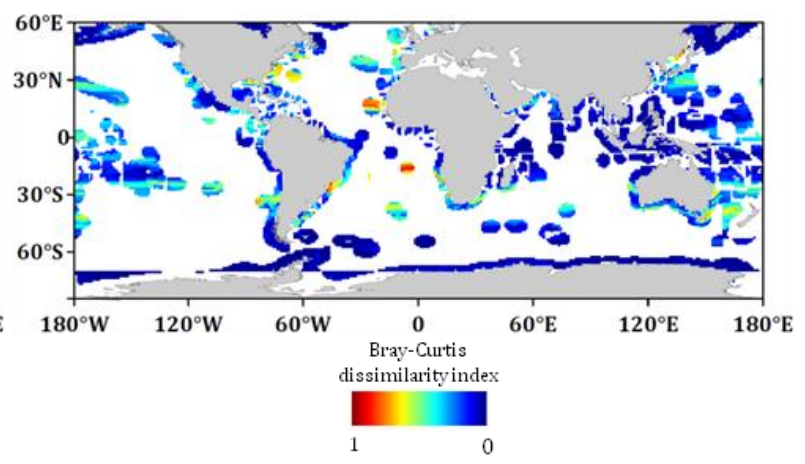

d
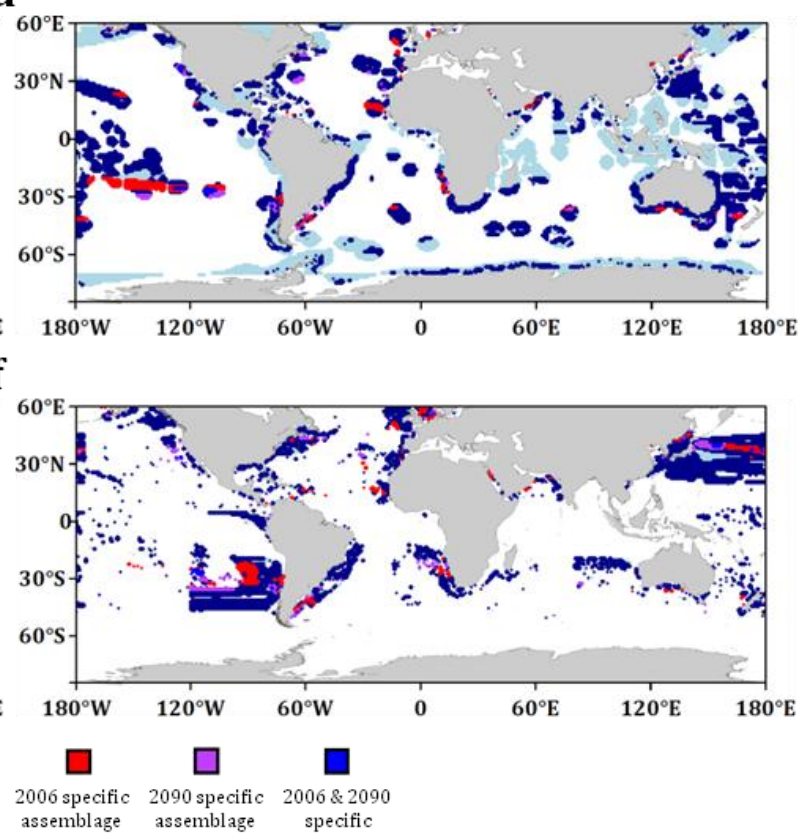
principal fisheries (4 last deciles ${ }^{20}$ ) and (b) Exclusive Economic Zones ${ }^{21}$. Assemblage changes in (c) Principal fisheries (d) Exclusive Economic Zones. Assemblage changes in (e) Principal fisheries (f) Exclusive Economic Zones with a Bray-Curtis dissimilarity index superior to 1/6. 


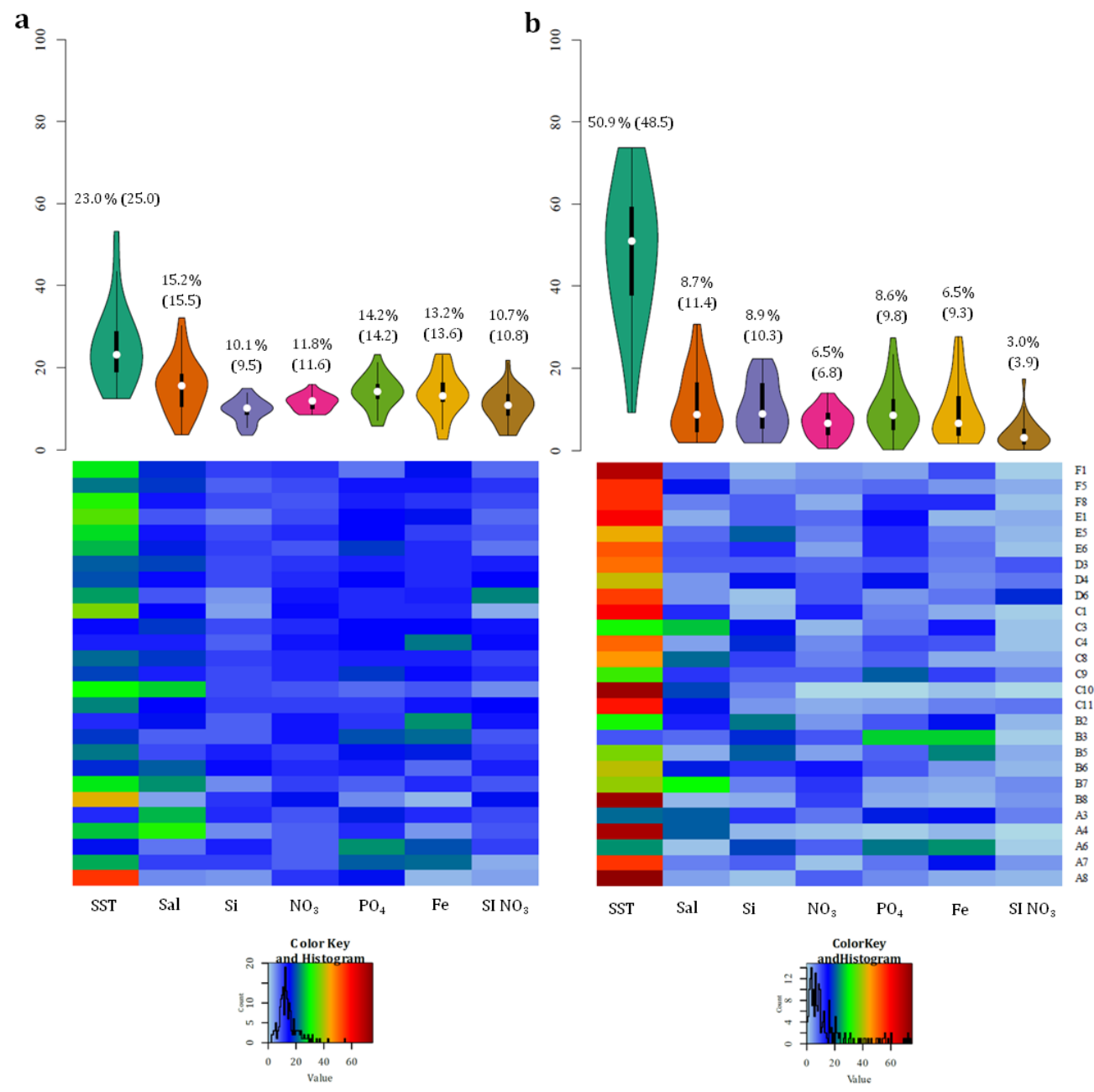

884 Supplementary Fig. 19 | Distributions and heat maps of the relative influences of the 885 different drivers in (a) defining single niches associated to the provinces from DALEX R 886 package $^{22}$ (b) driving climate change associated reorganizations of single provinces. Median 887 relative influence of Temperature is significantly higher than for all other environmental 888 parameters (Pairwise Wilcoxon test $\mathrm{p}<0.01$ for all parameters) in (a) defining the niches and (b) 889 driving province reorganization. It is also the case within individual size fractions for (b) but not for 890 (a). Respectively, Salinity (Sal) and Phosphate $\left(\mathrm{PO}_{4}\right)$, have second and third highest median relative 891 influences far behind Temperature whereas dissolved Silica and seasonality index of Nitrate (SI $892 \mathrm{NO}_{3}$ ) have the lowest median relative importance in (a). Numbers above violins are median (and 893 mean) relative influences. 


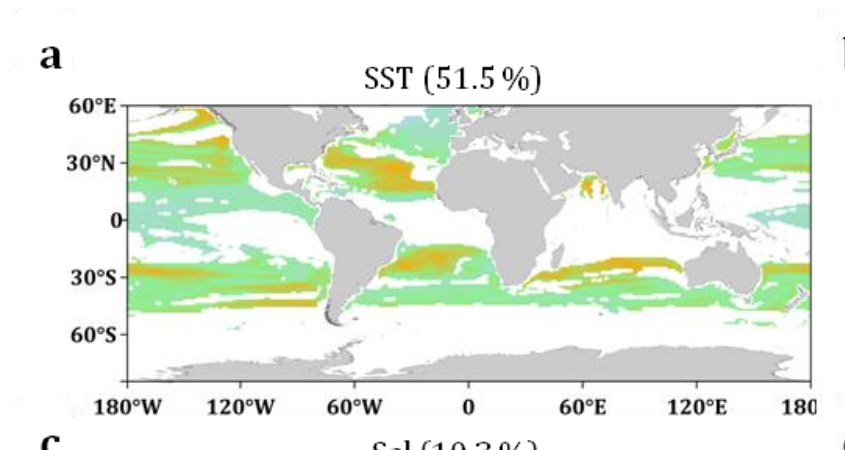

C

Sal $(10.3 \%)$
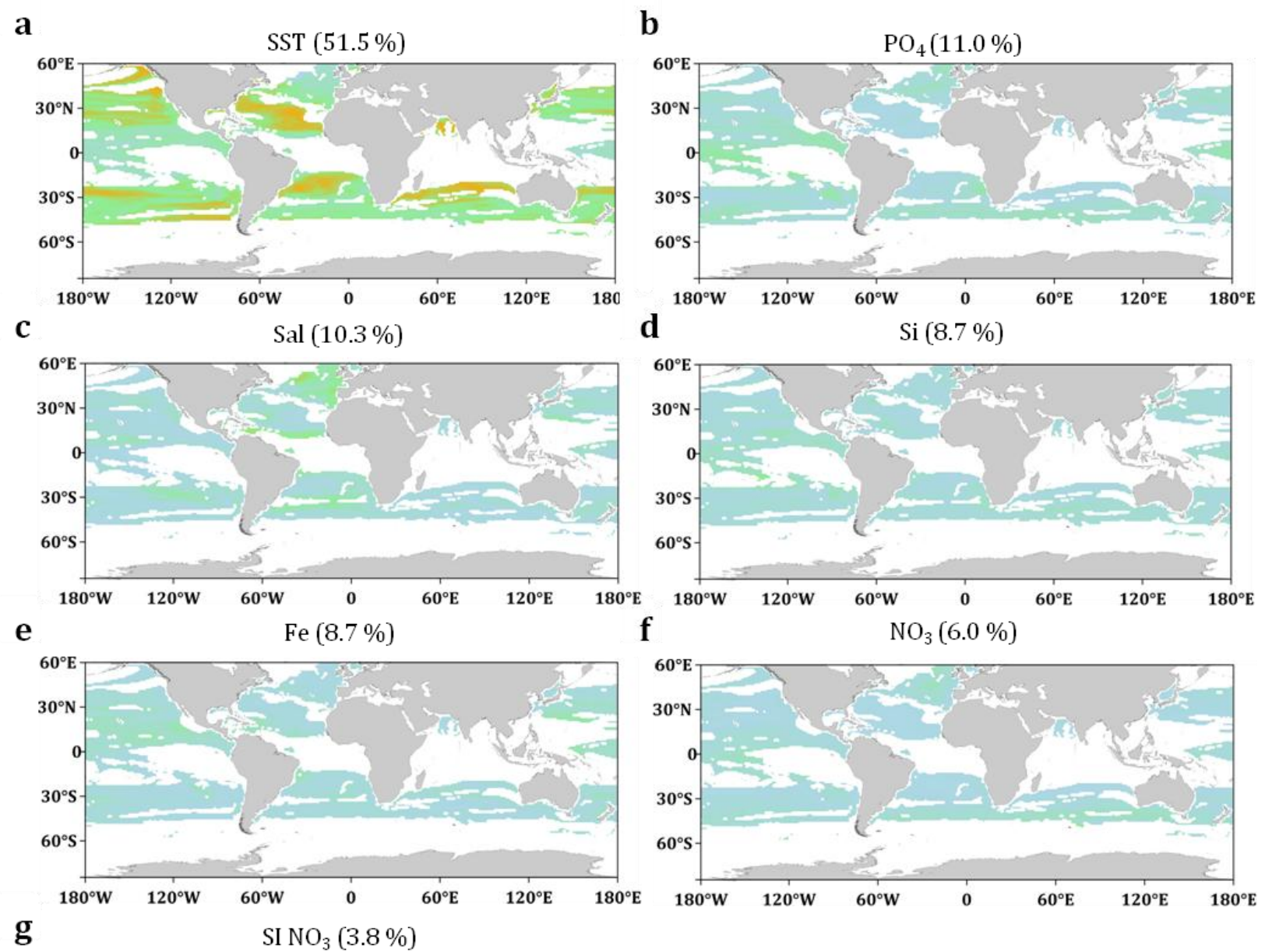

g

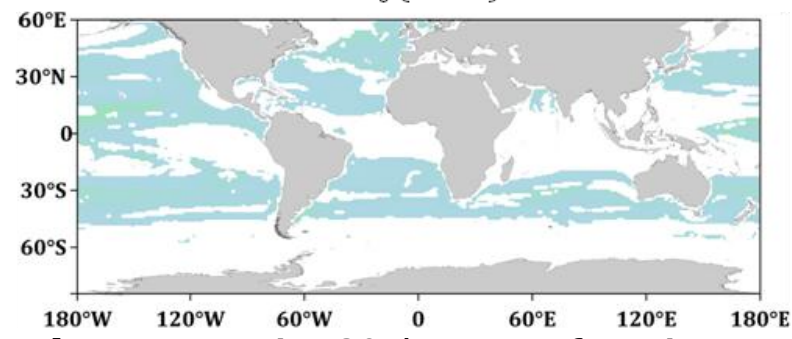

Driver impact

$(\%)$

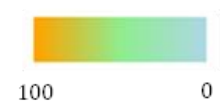

Supplementary Fig. 20 | Maps of environmental drivers' relative influences in driving

province reorganization. Each environmental parameter relative influence is quantified by considering only the variation of each parameter individually between present day and end of the century as defined in Barton et al. ${ }^{23}$ (Materials and Methods) and where a significant change is projected. Importantly the mean impact of SST (51.5 \%) is largely the highest. $\mathrm{PO}_{4}$ is the second most impacting drivers (11.0 \%). Contrary to supplementary Fig. 16, relative influence is calculated

901 here by combining all provinces together. Therefore, mean relative influences slightly differ especially for dissolved silica (Si). 
bioRxiv preprint doi: https://doi.org/10.1101/2020.10.20.347237; this version posted November 24,2020 . The copyright holder for this preprint (which was not certified by peer review) is the author/funder, who has granted bioRxiv a license to display the preprint in perpetuity. It is made available under aCC-BY-NC-ND 4.0 International license.

904

\begin{tabular}{ll}
\hline Model & Reference \\
\hline CESM1-BGC & Gent et al., 2011 \\
\hline GFDL-ESM2G & Dunne et al., 2013 \\
\hline GFDL-ESM2M & Dunne et al., 2013 \\
\hline HadGEM2-ES & Collins et al., 2011 \\
\hline IPSL-CM5A-LR & Dufresne et al., 2013 \\
\hline IPSL-CM5A-MR & Dufresne et al., 2013 \\
\hline MPI-ESM-LR & Giorgetta et al., 2013 \\
\hline MPI-ESM-MR & Giorgetta et al., 2013 \\
\hline NorESM1-ME & Bentsen et al., 2013
\end{tabular}

Supplementary Table 1 | Earth System models used to compute the mean model.

906 
bioRxiv preprint doi: https://doi.org/10.1101/2020.10.20.347237; this version posted November 24, 2020. The copyright holder for this preprint (which was not certified by peer review) is the author/funder, who has granted bioRxiv a license to display the preprint in perpetuity. It is made available under aCC-BY-NC-ND 4.0 International license.

907

\begin{tabular}{|c|c|c|c|c|c|}
\hline Fraction & Province & Climatic annotation & $\begin{array}{c}\text { Area } 2006-15 \\
\left(\mathrm{MKm}^{2}\right)\end{array}$ & $\begin{array}{c}\text { Area } 2090-99 \\
\left(\mathrm{MKm}^{2}\right)\end{array}$ & $\begin{array}{c}\text { Delta area } \\
\left(\mathrm{MKm}^{2}(\%)\right)\end{array}$ \\
\hline $180-2000$ & $\mathrm{~F} 1$ & polar & 82 & 73 & $-9(-11 \%)$ \\
\hline $180-2000$ & F5 & temperate & 44 & 26 & $-18(-41 \%)$ \\
\hline $180-2000$ & F8 & tropico-equatorial & 140 & 169 & $29(+21 \%)$ \\
\hline $20-180$ & E1 & polar & 97 & 84 & $-13(-13 \%)$ \\
\hline $20-180$ & E5 & tropico-equatorial & 119 & 145 & $+26(+22 \%)$ \\
\hline $20-180$ & E6 & temperate & 65 & 49 & $15(-23 \%)$ \\
\hline $5-20$ & D3 & temperate & 51 & 41 & $-10(-20 \%)$ \\
\hline $5-20$ & D4 & equatorial & 46 & 37 & $-8(-18 \%)$ \\
\hline $5-20$ & D6 & tropical & 65 & 97 & $32(+48 \%)$ \\
\hline $0.8-5$ & $\mathrm{C} 1$ & polar & 71 & 64 & $-6(-8 \%)$ \\
\hline $0.8-5$ & $\mathrm{C} 3$ & subtropical & 3,6 & 1,4 & $-2,2(-61 \%)$ \\
\hline $0.8-5$ & $\mathrm{C} 4$ & subtropical & 6 & 19 & $+13(+217 \%)$ \\
\hline $0.8-5$ & $\mathrm{C} 8$ & temperate & 33 & 15 & $-18(-54 \%)$ \\
\hline $0.8-5$ & $\mathrm{C9}$ & equatorial & 35 & 19 & $-16(-45 \%)$ \\
\hline $0.8-5$ & $\mathrm{C} 10$ & subtropical & 3.8 & 7.4 & $+3,6(+95 \%)$ \\
\hline $0.8-5$ & C11 & tropical & 49 & 86 & 37 (+75\%) \\
\hline $0.22-3$ & $\mathrm{~B} 2$ & subtropical & 5,1 & 6,7 & $+1,6(+31 \%)$ \\
\hline $0.22-3$ & B3 & equatorial & 33 & 32 & $-1(-0.3 \%)$ \\
\hline $0.22-3$ & B5 & tropical & 88 & 102 & $+13(+15 \%)$ \\
\hline $0.22-3$ & B6 & temperate & 30 & 35 & $+5(+17 \%)$ \\
\hline $0.22-3$ & B7 & temperate & 8 & 2 & $-6(-75 \%)$ \\
\hline $0.22-3$ & B8 & polar & 51 & 44 & $-7(-14 \%)$ \\
\hline $0-0.2$ & A3 & tropical & 101 & 114 & $+13(+13 \%)$ \\
\hline $0-0.2$ & $\mathrm{~A} 4$ & subtropical & 6 & 19 & $+13(+216 \%)$ \\
\hline $0-0.2$ & A6 & equatorial & 40 & 36 & $-4(-10 \%)$ \\
\hline $0-0.2$ & A7 & temperate & 1,7 & 1 & $-0,7(-41 \%)$ \\
\hline $0-0.2$ & A8 & polar & 81 & 67 & $-14(-17 \%)$ \\
\hline
\end{tabular}




\begin{tabular}{|c|c|c|c|c|c|c|c|c|}
\hline & Fraction $(\mu \mathrm{m})$ & SST & Sal & $\mathbf{S i}$ & NO3 & P04 & $\mathbf{F e}$ & SI N03 \\
\hline \multirow{7}{*}{$\begin{array}{c}\text { Niche } \\
\text { definition }\end{array}$} & $180-2000$ & 27,7 & 16,8 & 10,1 & 10,3 & 11,4 & 14 & 9,7 \\
\hline & $20-180$ & 29,7 & 13,3 & 8,9 & 10,7 & 16,3 & 13,2 & 7,9 \\
\hline & $5-20$ & 21,5 & 14,2 & 8,4 & 12,7 & 13,7 & 12,6 & 17 \\
\hline & $0,8-5$ & 22,6 & 17,3 & 9,2 & 12,3 & 13,4 & 14,5 & 10,8 \\
\hline & $0,22-3$ & 23,9 & 13,7 & 10,5 & 13 & 12,5 & 14,2 & 12,2 \\
\hline & $0-0,2$ & 27,1 & 16,4 & 9,3 & 9,5 & 17,9 & 12,1 & 7,6 \\
\hline & all & 25 & 15,5 & 9,5 & 11,6 & 14,2 & 13,6 & 10,8 \\
\hline \multirow{7}{*}{$\begin{array}{l}\text { Climate } \\
\text { change }\end{array}$} & $180-2000$ & 75,2 & 8,4 & 2,5 & 2,6 & 4,1 & 5,8 & 1,4 \\
\hline & $20-180$ & 71,7 & 4,2 & 7,3 & 3,9 & 8,7 & 3,3 & 1,0 \\
\hline & $5-20$ & 57,9 & 6,1 & 4,4 & 6,6 & 9,0 & 6,5 & 1,0 \\
\hline & $0,8-5$ & 54,9 & 13,4 & 7,2 & 5,5 & 9,7 & 5,9 & 3,6 \\
\hline & $0,22-3$ & 42,6 & 9,9 & 13,5 & 6,4 & 9,1 & 15,2 & 3,3 \\
\hline & $0-0,2$ & 42,3 & 18,9 & 6,6 & 6,4 & 12,1 & 10,8 & 2,9 \\
\hline & all & 51,5 & 10,3 & 8,7 & 6 & 11 & 8,7 & 3,8 \\
\hline
\end{tabular}

914 change. Note that in both cases (niche definition and climate change), the row 'all' is not the mean

915 over the size fractions. In the case of niche definition, this is due to a different number of niches in 916 each size class. In the case of climate change, relative influence is either calculated for single 917 provinces at a given grid point then recalculated for individual size class or calculated for all provinces together (row 'all'). 


\section{References}

921 1. Boyer, T. P. et al. WORLD OCEAN DATABASE 2013, NOAA Atlas NESDIS 72. Sydney Levitus, 922 Ed.; Alexey Mishonoc, Tech. Ed. (2013). doi:10.7289/V5NZ85MT

923 2. Gent, P. R. et al. The community climate system model version 4. J. Clim. (2011). 924 doi:10.1175/2011JCLI4083.1

925 3. Dunne, J. P. et al. GFDL's ESM2 global coupled climate-carbon earth system models. Part II: 926 Carbon system formulation and baseline simulation characteristics. J. Clim. (2013). 927 doi:10.1175/JCLI-D-12-00150.1

928 4. Collins, W. J. et al. Development and evaluation of an Earth-System model - HadGEM2. 929 Geosci. Model Dev. (2011). doi:10.5194/gmd-4-1051-2011

$930 \quad 5 . \quad$ Dufresne, J. L. et al. Climate change projections using the IPSL-CM5 Earth System Model: 931 From CMIP3 to CMIP5. Clim. Dyn. (2013). doi:10.1007/s00382-012-1636-1

932 6. Giorgetta, M. A. et al. Climate and carbon cycle changes from 1850 to 2100 in MPI-ESM 933 simulations for the Coupled Model Intercomparison Project phase 5. J. Adv. Model. Earth Syst. 934 (2013). doi:10.1002/jame.20038

935 7. Bentsen, M. et al. The Norwegian Earth System Model, NorESM1-M - Part 1: Description and 936 basic evaluation of the physical climate. Geosci. Model Dev. (2013). doi:10.5194/gmd-6-687-2013

937 8. van Vuuren, D. P. et al. The representative concentration pathways: An overview. Clim. 938 Change (2011). doi:10.1007/s10584-011-0148-z

939 9. Fawcett, T. An introduction to ROC analysis. Pattern Recognit. Lett. (2006). 940 doi:10.1016/j.patrec.2005.10.010

941 10. Wood, S. N. Stable and efficient multiple smoothing parameter estimation for generalized 942 additive models. J. Am. Stat. Assoc. (2004). doi:10.1198/016214504000000980

943 11. Ridgeway, G. gbm: Generalized Boosted Regression Models. R Packag. version 1.6-3.1 944 (2010).

945 12. Venables, W. N. \& Ripley, B. D. Modern Applied Statistics with S Fourth edition by. World 946 (2002). doi:10.2307/2685660

947 13. Breiman, L. \& Cutler, A. Breiman and Cutler's random forests for classification and 948 regression. Packag. 'randomForest' (2012). doi:10.5244/C.22.54 
949 14. Jaccard, P. Distribution comparée de la flore alpine dans quelques régions des Alpes

950 occidentales et orientales. Bull. la Murithienne (1902).

951 15. Delmont, T. O. et al. Nitrogen-fixing populations of Planctomycetes and Proteobacteria are 952 abundant in surface ocean metagenomes. Nat. Microbiol. (2018). doi:10.1038/s41564-018-0176-9

953 16. Aumont, O., Ethé, C., Tagliabue, A., Bopp, L. \& Gehlen, M. PISCES-v2: An ocean 954 biogeochemical model for carbon and ecosystem studies. Geosci. Model Dev. (2015). 955 doi:10.5194/gmd-8-2465-2015

956 17. Reygondeau, G. et al. Dynamic biogeochemical provinces in the global ocean. Global 957 Biogeochem. Cycles (2013). doi:10.1002/gbc.20089

958 18. Fay, A. R. \& McKinley, G. A. Global open-ocean biomes: Mean and temporal variability. Earth 959 Syst. Sci. Data (2014). doi:10.5194/essd-6-273-2014

960 19. Michelangeli, P. A., Vrac, M. \& Loukos, H. Probabilistic downscaling approaches: Application 961 to wind cumulative distribution functions. Geophys. Res. Lett. (2009). doi:10.1029/2009GL038401

962 20. Watson, R. A. A database of global marine commercial, small-scale, illegal and unreported 963 fisheries catch 1950-2014. Sci. Data (2017). doi:10.1038/sdata.2017.39

964 21. Flanders Marine Institute (2018). Maritime Boundaries Geodatabase: Maritime Boundaries 965 and Exclusive Economic Zones (200NM), version 10. (2018). doi:https://doi.org/10.14284/313.

966 22. Biecek, P. DALEX: explainers for complex predictive models. J. Mach. Learn. Res. 19, 1-5 967 (2018).

968 23. Barton, A. D., Irwin, A. J., Finkel, Z. V. \& Stock, C. A. Anthropogenic climate change drives shift 969 and shuffle in North Atlantic phytoplankton communities. Proc. Natl. Acad. Sci. (2016). 970 doi:10.1073/pnas.1519080113 